\title{
The primate working memory networks
}

\author{
CHRISTOS CONSTANTINIDIS \\ Wake Forest University School of Medicine, Winston-Salem, North Carolina \\ and \\ EMMANUEL PROCYK \\ Inserm U3\%1, Institut Fédératif des Neurosciences de Lyon, Bron, France
}

\begin{abstract}
Working memory has long been associated with the prefrontal cortex, since damage to this brain area can critically impair the ability to maintain and update mnemonic information. Anatomical and physiological evidence suggests, however, that the prefrontal cortex is part of a broader network of interconnected brain areas involved in working memory. These include the parietal and temporal association areas of the cerebral cortex, cingulate and limbic areas, and subcortical structures such as the mediodorsal thalamus and the basal ganglia. Neurophysiological studies in primates confirm the involvement of areas beyond the frontal lobe and illustrate that working memory involves parallel, distributed neuronal networks. In this article, we review the current understanding of the anatomical organization of networks mediating working memory and the neural correlates of memory manifested in each of their nodes. The neural mechanisms of memory maintenance and the integrative role of the prefrontal cortex are also discussed.
\end{abstract}

Working memory is the term commonly used for the ability to maintain information in memory over a time span of a few seconds. Working memory constitutes a core component of higher cognitive functions including language, problem solving, and reasoning (Baddeley, 1992). Lesion studies first localized working memory functions in the cortical surface of the frontal lobe (Jacobsen, 1936; Milner, 1963). Neurophysiological recordings subsequently provided a neural correlate of working memory in the sustained discharges of neurons that persisted even after the offset of brief stimuli that monkeys were trained to remember and recall (Fuster \& Alexander, 1971). Individual neurons represent particular features and spatial locations so that the activity of the prefrontal population can encode a remembered stimulus. The part of the visual space in which stimulus appearance can produce sustained activation has been termed the neuron's memory field, analogous to the receptive field of neurons that respond to sensory stimulation ( $\mathrm{Fu}-$ nahashi, Bruce, \& Goldman-Rakic, 1989).

Neurons with memory-related responses have since been reported in multiple brain regions-for example, the inferior temporal and posterior parietal cortices, which are the end stages of the ventral and dorsal visual pathways, respectively (Andersen, Essick, \& Siegel,

C.C. was supported by the McDonnell Foundation and the Whitehall Foundation, and E.P. was supported by the Fyssen Foundation and the NRJ Foundation. This work is dedicated to the memory of Patricia S. Goldman-Rakic, our mentor, friend, and unending source of inspiration. Correspondence concerning this article should be addressed to C. Constantinidis, Department of Neurobiology and Anatomy, Wake Forest University School of Medicine, Medical Center Blvd., WinstonSalem, NC 27157-1010 (e-mail: cconstan@wfubmc.edu).
1987; Fuster \& Jervey, 1981). The prefrontal cortex is reciprocally connected to these areas in a well organized and systematic fashion: The dorsal prefrontal cortex (areas 8 and 46) is interconnected with the posterior parietal cortex, whereas the ventral prefrontal cortex (areas 12 and 45) is linked to the inferior temporal cortex. On the basis of this organization, Patricia Goldman-Rakic (1988) proposed that working memory is mediated by the sustained activity of neurons in parallel, distributed cortical networks. More recently, imaging modalities (PET and fMRI) have verified the concurrent activation of multiple human brain areas during performance of cognitive tasks that engage working memory, confirming the findings of the monkey neurophysiological studies (Courtney, Ungerleider, Keil, \& Haxby, 1997; Jonides et al., 1993; Ungerleider, Courtney, \& Haxby, 1998).

Over the last decade, great progress has been made in understanding the organization of the working memory networks and the functional specialization of brain areas that constitute them. Here, we will provide an update of the anatomical and physiological details of the working memory networks, focusing on the brain of the rhesus monkey as the best studied model. The prefrontal cortex will be the point of origin for our review. We will examine the organization of the prefrontal cortex and its connections with the sensory pathways - namely, the ventral and dorsal visual pathways and the somatosensory, auditory, gustatory, and olfactory cortices. We will also examine the function of the medial temporal system and that of limbic and subcortical structures. Finally, we will discuss the differential functions of brain regions comprising the network and the integrative role of the prefrontal cortex. 


\section{EXPERIMENTAL INVESTIGATION OF WORKING MEMORY}

Working memory can be engaged and manifested in tasks that require a subject to remember a briefly presented stimulus. For example, an experimenter may bait one of two food wells in view of a monkey in a Wisconsin General Testing Apparatus and lower a screen obstructing the monkey's view for a period of a few seconds. Once the screen is raised again, the monkey is allowed to uncover one well and retrieve the treat. In order to correctly perform such a task, the subject must keep in memory the spatial location of the food item over the delay period, when no stimulus is visible. This visuospatial memory is mediated by neuronal discharges in a network of brain areas that can be investigated in vivo, with microelectrode recordings. However, neurons also discharge in response to other aspects of the subject's be- havior over the delay period - for example, the planning and execution of eye movements.

In order to identify neuronal discharges related to working memory, a number of tasks have been devised that tightly control behavioral variables (see Figure 1). One of the simplest and most extensively used, the oculomotor delayed response (ODR) task, requires a subject to foveate a bright spot on a screen and maintain fixation while a square is flashed briefly on the visual periphery (Funahashi et al., 1989). The square is extinguished, and over a period of a few seconds only the fixation point is visible on the screen. When the latter is also turned off, subjects are required to indicate the cued location by shifting their eyes to where the square had previously appeared on the screen. In such a task, the visual display and the subject's gaze in the interval before cue presentation are identical to those in the interval after cue presentation. Therefore, any difference in neuronal activity
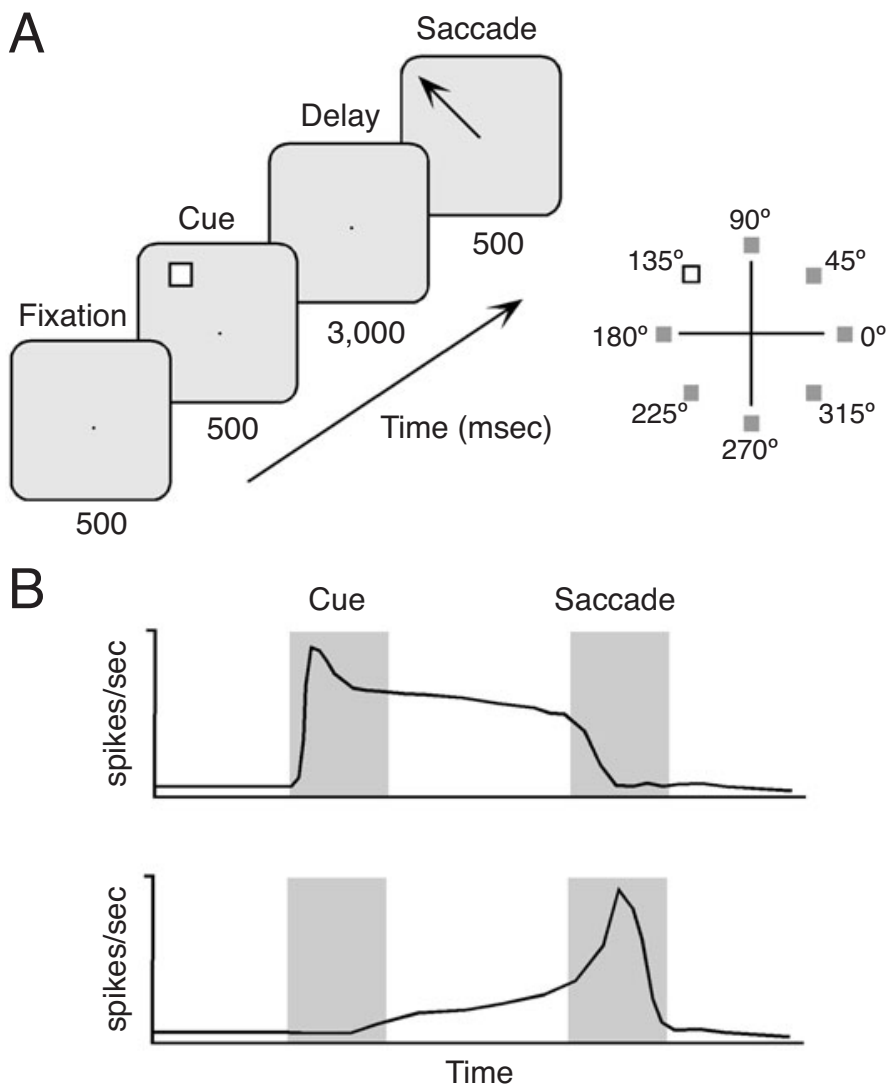

Figure 1. (A) The ocolumotor delayed response task. Panels represent successive frames of the subject's screen during the execution of the task. The inset on the right illustrates that the cue may appear at any of eight spatial locations around the fixation point, randomly interleaved during the experiment. (B) Schematic illustrations of two types of neuronal responses during the execution of the task. The top panel illustrates a transient response to the cue that is sustained throughout the delay period. The bottom panel shows a neuron that discharges in accelerating fashion before the onset of the eye movement. Neurons with activation at any combination of task epochs have been reported in the prefrontal cortex and elsewhere. 
may be attributable only to the spatial cue. Furthermore, the location of the cue varies randomly from trial to trial. This prevents the subject from predicting and anticipating the appearance of the cue and makes it possible to identify neurons "tuned" for the memory of specific locations. Individual neurons encode the remembered location of particular stimuli, further suggesting that elevated activity over the delay period is not simply a general effect of arousal or anticipation of reward.

Although the ODR task controls for a number of behavioral variables, neuronal activity recorded over its delay period may still be indicative of several processes other than working memory. Neurons may simply discharge in preparation of the saccade, which is perfectly predictable after the appearance of the cue and covaries with the cued location. More complex tasks have been devised to dissociate the two factors. In an antisaccade task, subjects are required to move their eyes away from the location of the cue; it is then possible to test whether the discharges of a neuron represent the location of the visual stimulus or the direction of the eye movement. Similarly, a spatial matching-to-sample task requires subjects to observe a sequence of stimuli and to release a lever when one appears at the location of the initial stimulus. Since the motor response is identical in every trial, any differences in neuronal responses may be due only to the location of the remembered stimulus. Even in this case, however, it is difficult to distinguish between the effects of spatially directed attention to the effects of memory for the cued location, and it is important to realize the interplay of multiple factors that influence neuronal activity.

Tasks that require the monkey to remember the identity rather than the spatial location of a stimulus have revealed neurons selectively tuned for the color and form of remembered visual stimuli as well as for stimuli of other sensory modalities. The brain areas thus activated during the maintenance of information in memory are presented next.

\section{PREFRONTAL CORTEX}

The primate prefrontal cortex is defined as the cortex anterior to the arcuate sulcus and connected to the mediodorsal (MD) nucleus of the thalamus (see Figure 2). It can be subdivided into a lateral, a medial, and an orbital aspect. It receives multimodal sensory and limbic input from several pathways, reviewed in detail below, which project on discrete prefrontal subdivisions. In turn, the prefrontal cortex projects to premotor cortical areas and subcortical structures.

Part of the difficulty in appreciating the results of different studies and in understanding the specialized roles of prefrontal subdivisions has been the use of alternative anatomical terminologies. The lateral prefrontal cortex in particular has been further divided into a dorsal and a ventral component. The terms ventral and dorsal have been used rather loosely, however, so that dorsolateral

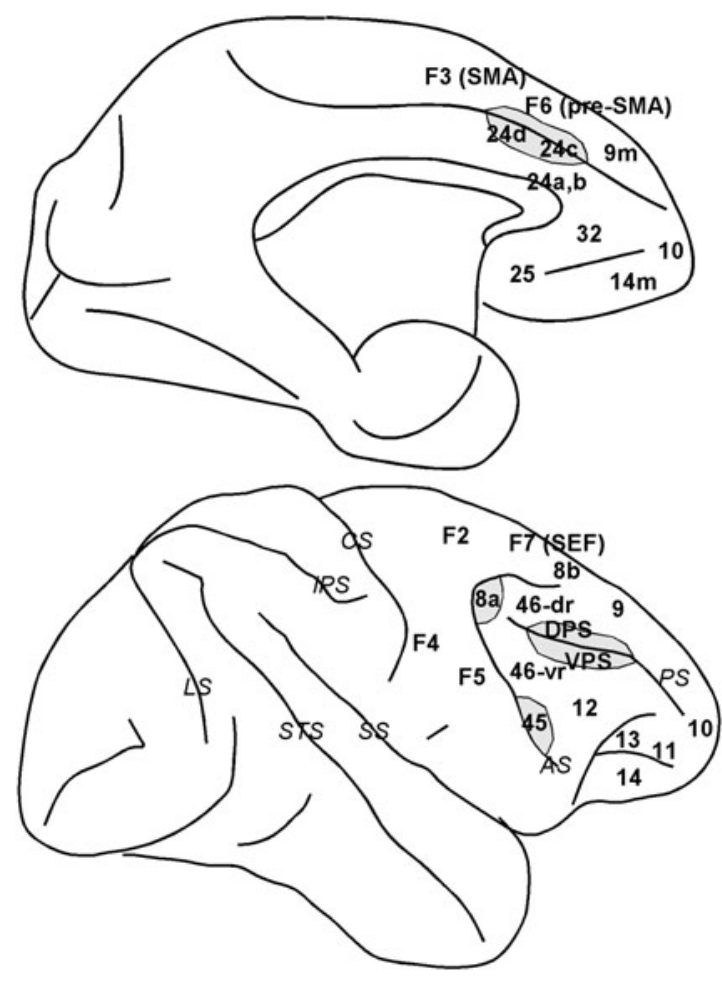

Figure 2. Schematic diagram of the macaque brain depicting prefrontal and cingulate areas. Top diagram: medial view of the brain. Bottom diagram: lateral view of the brain. Gray regions denote banks of a sulcus (only partially unfolded). Abbreviations of cortical areas: 46-dr, dorsal rim of area 46; 46-vr, ventral rim of area 46; DPS, dorsal principal sulcal area; SEF, supplementary eye field; SMA, supplementary motor area; VPS, ventral principal sulcal area. Abbreviations of sulci (in italics): AS, arcuate sulcus; CS, central sulcus; IPS, intraparietal sulcus; LS, lunate sulcus; PS, principal sulcus; SS, sylvian sulcus (lateral fissure); STS, superior temporal sulcus.

prefrontal cortex may denote the superior convexity medial to the principal sulcus, corresponding to area 9 (Iba $\&$ Sawaguchi, 2003); the cortex lining both banks of the principal sulcus, part of area 46 (White \& Wise, 1999); the dorsal bank of the principal sulcus and the rim of the arcuate suclus, parts of areas 46 and $8 \mathrm{a}$ (Constantinidis, Franowicz, \& Goldman-Rakic, 2001b); or the area extending all the way to the frontal pole, including areas 9 and 10 (Wallis, Anderson, \& Miller, 2001). The ventrolateral prefrontal cortex similarly shrinks or expands according to each of these definitions. We make an attempt to use anatomical terms clearly and define the boundaries of areas and subdivisions.

\section{Lateral Prefrontal Cortex}

Walker (1940) initially identified multiple cytoarchitectonic areas on the lateral aspect of the macaque brain (Figure 2): areas 8a (encompassing the frontal eye field) and 45 lining the banks of the superior and inferior limbs of the arcuate sulcus, respectively; area $8 \mathrm{~b}$ just medial to the arcuate; areas 9 and 12 in the superior and inferior 
convexities of the cortex, respectively; area 46 lining both banks of the principal sulcus; and area 10 covering the frontal pole. This nomenclature has persisted with little modification, except for the further subdivision of area 46 into four areas: that lining the dorsal rim, those lining the dorsal and the ventral banks of the principal sulcus, and that lining the ventral rim of the principal sulcus. These areas have been termed 46-dr, 46-d, 46-v, and 46vr, respectively (Preuss \& Goldman-Rakic, 1991). Alternatively, the most caudal aspect of area 46 is referred to as area 9/46 (Petrides, 2000). Since area 46 is still referred to as a unitary region by many investigators, in this review we will refer to the anatomical location of each area 46 subdivision with the explicit description of its location relative to the principal sulcus (i.e., dorsal rim area, dorsal principal sulcal area, ventral principal sulcal area, and ventral rim area).

The sensory selectivity of neurons in each of the lateral prefrontal areas mirrors to a large extent the functional properties of the terminal areas of the sensory pathways projecting to them. In recent years, neuronal responses of the lateral prefrontal cortex (and other highorder areas) have been shown to encode not just the sensory attributes of stimuli, but more abstract qualities such as categories and numbers, as well (Freedman, Riesenhuber, Poggio, \& Miller, 2002; Nieder, Freedman, $\&$ Miller, 2002). Overlapping populations of prefrontal neurons are activated during the interval of sensory stimulation, over delay periods of no stimulation, and around the time of motor responses (Funahashi et al., 1989). The prefrontal cortex projects back to all the areas from which it receives sensory input as well as to structures with motor functions, including the premotor cortex, the superior colliculus, and the basal ganglia, though not directly to the primary motor cortex.

The representation of sensory, mnemonic, and motor information is generally not topographic (e.g., visuotopic) in the prefrontal cortex. Instead, the same retinal location and eye movement direction is represented multiple times across the cortical surface (Constantinidis, Franowicz, \& Goldman-Rakic, 2001a). Anatomical evidence suggests a highly regular pattern of axonal terminations both from within the prefrontal cortex and from association cortices, forming repeating, interdigitated stripes (Kritzer \& Goldman-Rakic, 1995; Pucak, Levitt, Lund, \& Lewis, 1996). Nevertheless, the underlying principles of prefrontal functional organization remain elusive.

One possible explanation for the absence of topological mapping of stimulus dimensions, as in the primary sensory cortex, is that the prefrontal cortex is organized in multiple intersecting and overlapping networks of associated attributes (Fuster, 2003). However, several lines of evidence suggest at least a local organization in neuronal coding properties. Narrow cortical lesions and local, chemical inactivation affect only a restricted area of visual space, typically in the contralateral hemifield, an effect known as a mnemonic scotoma (Funahashi,
Bruce, \& Goldman-Rakic, 1993; Sawaguchi \& GoldmanRakic, 1991, 1994). Simultaneous recordings from electrodes spaced $0.2-0.3 \mathrm{~mm}$ apart similarly indicate that nearby neurons represent adjacent spatial locations (Constantinidis et al., 2001a). These results suggest at least a coarse topography, possibly involving the entire visual hemifield represented in repeating cortical modules.

Why would the representation of a stimulus or a motor target be replicated multiple times across the prefrontal cortex? Although no definitive answer is currently available, theoretical studies provide some possible explanations. The brain is able to flexibly generate variable responses to identical stimuli depending on the context in which they appear. The absence of a one-to-one correspondence between sensory stimuli and motor responses makes the replication of stimulus representations in the prefrontal cortex inevitable. Recent studies have formally demonstrated that a neural circuit that contains multiple representations of the same sensory stimulus, mapped to multiple motor outcomes but each modulated in a different fashion by contextual factors, can effectively act as a switch, producing different motor outcomes depending on the rule or context enforced (Salinas, 2004).

The discharges of prefrontal neurons are indeed modulated by factors other than sensory stimulation or motor responses. Responses to the same operant stimuli vary depending on the expectation of reward when the latter varies from trial to trial (Leon \& Shadlen, 1999). A similar modulation of neuronal responses to identical stimulation has been observed in animals trained to perform a number of alternative tasks requiring association of the same stimulus with different possible motor choices, according to different rules (Asaad, Rainer, \& Miller, 2000; Wallis, Anderson, \& Miller, 2001; White \& Wise, 1999). Finally, prefrontal neurons preferentially represent the attributes of stimuli that are behaviorally relevant and require attention, over identical stimuli that are deemed as uninformative or distracting for the purposes of a behavioral task (Everling, Tinsley, Gaffan, \& Duncan, 2002; Rainer, Asaad, \& Miller, 1998).

\section{Orbitofrontal Cortex}

The orbital frontal cortex (OFC) includes areas 10,11, 13, and 14 (see Figure 2). It is interconnected to the amygdala, gustatory and olfactory cortices, temporal cortex, lateral prefrontal cortex, and anterior cingulate, as well as to the ventral striatum, mesencephalic structures, and hypothalamus (Barbas, 2000). This pattern of connections suggests that the contribution of the OFC to behavior relates to motivation and emotion (Rolls, 2002). Lesion studies in humans and nonhuman primates reveal no clear deficits in working memory tasks after OFC lesions and, thereby, a strong functional dissociation between the OFC and the lateral prefrontal cortex (Bechara, Damasio, Tranel, \& Anderson, 1998; Wallis, Dias, Robbins, \& Roberts, 2001). Indeed, OFC lesions induce deficits related to emotional reactions, social behaviors, 
reversal learning, associative memory, and adaptation to reward change (Baxter, Parker, Lindner, Izquierdo, \& Murray, 2000; Meunier, Bachevalier, \& Mishkin, 1997; Passingham, 1993).

In line with lesion data, unit recordings in the OFC show activity related to reward discrimination, expectation, and preference (K. Hikosaka \& Watanabe, 2000; Rosenkilde, Bauer, \& Fuster, 1981; Tremblay \& Schultz, 1999; Wallis \& Miller, 2003b). However, in contrast with the findings of lesion studies, unit recordings reveal delay-related discharges that contain information related to cues given in delayed response tasks and to reward expectation (K. Hikosaka \& Watanabe, 2000; Rosenkilde et al., 1981; Wallis \& Miller, 2003b). Studies that focused on this OFC activity provide insights into its functional role in working memory. OFC delay activity codes for expected reward even in tasks in which reward is not part of the memory component of the task (K. Hikosaka \& Watanabe, 2000). It has little to do with the impending behavioral response properties, but it is influenced by motivational factors. More-over, reward-related information appears earlier in OFC than in lateral prefrontal cortex (Wallis \& Miller, 2003b). Thus, OFC may not have a role in active maintenance of information but could have a role in representing goals and their motivational components (preferences), and hence could be a source of target-value and reward-related information to be combined with response-related representations in working memory. In this context, we shall note that it is the cognitive binding among memorized items, outcome expectations (reward), and impending response plans that enables the organization of goal-directed behaviors (Fuster, 2001).

\section{Medial Prefrontal Cortex}

Areas traditionally considered as part of the monkey medial prefrontal cortex include the supplementary eye field (alternatively considered part of the premotor cortex - area F7 in Figure 2, bottom) and the medial aspects of areas 9 and 14 ( $9 \mathrm{~m}$ and $14 \mathrm{~m}$ in Figure 2, top). Area 24 is also often grouped with the medial prefrontal cortex; however, here we will examine it independently as part of the anterior cingulate cortex.

The medial prefrontal cortex has received much less neurophysiological scrutiny than the lateral prefrontal cortex, in the monkey. On the basis of its pattern of anatomical inputs, visual, somatosensory, and olfactory responses would be expected in distinct medial frontal divisions (Barbas, Ghashghaei, Dombrowski, \& Rempel-Clower, 1999). Persistent, memory-related discharges have been described in the supplementary eye field (Russo \& Bruce, 1996). This activity has been shown to be influenced by the sensorimotor association tasks that monkeys have been trained to perform; for example, antisaccades generally produce stronger responses than prosaccades to the same direction (Schlag-Rey, Amador, Sanchez, \& Schlag, 1997). In addition, neurons in the supplementary eye field have been shown to discharge in response to perceived errors in eye movement tasks (Stuphorn, Taylor, $\&$ Schall, 2000). Both of these findings are consistent with the idea that medial frontal structures are involved with the monitoring of self behavior and the potential conflict between sensory stimuli, actions, and expectations.

Other factors influencing neuronal responses in the medial prefrontal cortex include the object-centered frame of reference of eye movements, reward expectation, or rules that the animals have been trained to perform (Amador, Schlag-Rey, \& Schlag, 2000; Matsumoto, Suzuki, \& Tanaka, 2003; Olson \& Gettner, 1995).

\section{FRONTAL CORTEX BEYOND PREFRONTAL}

\section{Anterior Cingulate Cortex}

The cingulate cortex is located on the medial surface of the hemispheres, covering the entire length of the corpus callosum. It is divided into anterior and posterior regions. Moreover, the cortex of the cingulate sulcus is distinguished from the cortex of the cingulate gyrus. The monkey anterior cingulate cortex (ACC) comprises areas $24 \mathrm{a}, 24 \mathrm{~b}, 24 \mathrm{c}$, and $24 \mathrm{~d}$, the precise delineation of which varies from author to author. Recently, much attention has been drawn to area $24 \mathrm{c}$, which lines the inferior and superior banks of the cingulate sulcus and is bounded posteriorly by area $24 \mathrm{~d}$. Area $24 \mathrm{c}$ contains the rostral cingulate motor area (CMAr; Dum \& Strick, 1991, 1993). In comparison with caudal cingulate motor areas, the more anterior part of the cingulate sulcus (including CMAr) is characterized by significant connections with the presupplementary motor area and lateral prefrontal areas (Hatanaka et al., 2003; Y. Wang, Shima, Sawamura, \& Tanji, 2001). Area 24c projects onto the median and caudal parts of the principal sulcus (areas 46, 8a, 8b, 9, and 12; Barbas \& Mesulam, 1985; Bates \& Goldman-Rakic, 1993; Lu, Preston, \& Strick, 1994; McGuire, Bates, \& Goldman-Rakic, 1991). The density and significance of these connections is debatable, especially in light of recent studies (Takada et al., 2004), but they are consistent with a particular role of this subdivision of ACC in higher order cognitive functions. As much of the medial prefrontal frontal cortex, ACC receives strong dopaminergic inputs (S. M. Williams \& Goldman-Rakic, 1993).

Relation to lateral PFC. Initially, thanks to human brain imaging studies, consistent activation of the homolog part of monkey $24 \mathrm{c}$ was observed during most cognitive tasks. Most human brain imaging studies devoted to high-order cognition reported joint lateral prefrontal and ACC activations, in particular when the tasks used were complex or necessitated active control on behavior (e.g., Frith, Friston, Liddle, \& Frackowiak, 1991; Koski \& Paus, 2000; Paus, Petrides, Evans, \& Meyer, 1993). The most recent reviews on prefrontal functions underline the importance of these facts (Duncan \& Owen, 2000; Miller \& Cohen, 2001; Paus, 2001). Nonetheless, 
activations of these two regions are dissociable in functional terms (MacDonald, Cohen, Stenger, \& Carter, 2000; Posner \& DiGirolamo, 1998).

Role in working memory. It is now widely accepted that, although dissociated in some ways, systems involved in higher brain functions (storing, monitoring, and manipulating information in memory) establish strong relationships and interactions or even overlap with those concerned with motivation and emotion. For instance, in her description of distributed functions in several parallel systems, Goldman-Rakic (1988) illustrated how interconnected prefrontal dorsolateral and parietal areas shared common connections with the ACC, thereby underlying a link between working memory and motivation.

The involvement of monkey ACC in working memory tasks has been suggested by brain imaging (Inoue, Mikami, Ando, \& Tsukada, 2004). Among neurophysiological experiments in which ACC unit activity in monkeys was studied, only a few reported neural activity recorded during spatial delay tasks (Akkal, Bioulac, Audin, \& Burbaud, 2002; Isomura, Ito, Akazawa, Nambu, \& Takada, 2003; Niki \& Watanabe, 1976; Procyk \& Joseph, 2001). However, although tonic activity during memory delays has been reported in electrophysiological studies, the authors acknowledge that information contained in ACC delay activity has little to do with a potential memory buffer coding specifically for location of targets or direction of movements (Akkal et al., 2002; Isomura et al., 2003; Procyk \& Joseph, 2001). On the other hand, ACC activity is strongly influenced by reward expectation and by various parameters related to the selection of action based on expected rewards (Akkal et al., 2002; Matsumoto et al., 2003; Niki \& Watanabe, 1976; Procyk \& Joseph, 2001; Procyk, Tanaka, \& Joseph, 2000; Shidara \& Richmond, 2002; Shima \& Tanji, 1998). Most of the data, including those related to the role of ACC in error detection, converge toward a key function of ACC in behavior evaluation. Lesion studies strongly support this view (Hadland, Rushworth, Gaffan, \& Passingham, 2003; Rushworth, Hadland, Gaffan, \& Passingham, 2003). Indeed, expectation of reward associated to action and error detection are part of a unique function by which the adequacy of behavior is evaluated.

Thus, the role of ACC in working memory and its particular relationship with lateral prefrontal cortex remain in question. It is possible that the unified representation of goal-directed action in complex cognitive tasks depends on the parallel coding of integrated motivation-action information in ACC and actively memorized information as is seen in lateral prefrontal cortex. Yet other, nonparallel interactions may take place between these two structures, in particular when error or conflict detection triggers action selection adjustment (Miller \& Cohen, 2001).

\section{Premotor Cortex}

Premotor areas are divided into mesial (areas F3 [supplementary motor area] and F6 [presupplementary motor area]), lateral dorsal (areas F2, F7-supplemen- tary eye field), and lateral ventral (F4, F5) territories (Matelli, Luppino, \& Rizzolatti, 1991). One main factor of subdivision of premotor areas is related to effector maps. Each premotor area supports at least one body representation that has been delineated by microstimulation (Godschalk, Mitz, van Duin, \& van der Burg, 1995; Luppino, Matelli, Camarda, Gallese, \& Rizzolatti, 1991; Mitz \& Wise, 1987). In addition, several eye fields have been described in lateral and medial premotor areas (Huerta, Krubitzer, \& Kaas, 1986, 1987; Schlag \& SchlagRey, 1987; Y. Wang, Matsuzaka, Shima, \& Tanji, 2004).

Areas F6 and F7 (anterior premotor) receive input from the prefrontal cortex and project to the other premotor areas F2, F3, F4, and F5, which in turn project to the primary motor cortex and the spinal cord (Dum \& Strick, 1991; Rizzolatti \& Luppino, 2001). Connections between area 46 and lateral premotor areas extend the dorsoventral dissociation (Barbas \& Pandya, 1987; Y. Wang, Shima, Isoda, Sawamura, \& Tanji, 2002; WatanabeSawaguchi, Kubota, \& Arikuni, 1991).

Function. The top-to-bottom connectivity from prefrontal to primary motor cortex reinforces a pyramidal view of the cortical organization in the frontal cortex as well as of the functional roles of its subdivisions. Although recent brain imaging studies suggest that the lateral frontal cortex is organized as a cascade of executive processes from anterior prefrontal to premotor regions, it is also plausible that executive networks are to some degree heterarchical instead of purely hierarchical (Fuster, 2001; Koechlin, Ody, \& Kouneiher, 2003). Thus, whether or not the frontal cortex is purely hierarchically organized in terms of cognitive function is debatable, and a description of working memory networks is central to the debate. In particular, it is important to compare prefrontal and premotor tonic activities and their times of occurrence during cognitive tasks.

The supplementary motor area (SMA) and the PreSMA have a crucial role in sequence planning, and lateral premotor areas play a crucial role in planning visually guided movements, more specifically during conditional motor learning (Nakamura, Sakai, \& Hikosaka, 1998; Shima, Mushiake, Saito, \& Tanji, 1996; Tanji \& Shima, 1994; Wise, Murray, \& Gerfen, 1996). For instance, premotor dorsal and ventral neurons respond differently to identical stimuli that instruct different actions (Boussaoud \& Wise, 1993; di Pellegrino \& Wise, 1993b). This is to say that although they process spatial or motor parameters (Crammond \& Kalaska, 1994; Jouffrais \& Boussaoud, 1999; Messier \& Kalaska, 2000), premotor areas are involved in more than basic motor control.

We focus on lateral premotor areas since several attempts have been made either to compare activity in these areas with those in prefrontal cortex or to detail neural activity and information coding during memory delay. Although delay tonic activity can be observed in prefrontal and premotor areas, in several studies it has been reported that, on average, prefrontal cell activity differs from premotor cell activity in that it is more closely 
related to stimulus information than to motor plan (Boussaoud \& Wise, 1993; di Pellegrino \& Wise, 1993b; Wallis $\&$ Miller, 2003a). In a double delay task, latencies of phasic and tonic activities are shorter in prefrontal than in premotor cortex, which in turn discharges more intensely later in the delay (di Pellegrino \& Wise, 1991). These results support the idea of a transfer of information from prefrontal to premotor cortex and from cognitive to motor content, during delay periods that bridge instruction and motor response. However, this may not be always the case; premotor activity can have shorter latency than prefrontal activity (Wallis \& Miller, 2003a). Moreover, in a spatial delayed response task, prior information about distance of the target is reflected in premotor activity during the delay period well before movement initiation and begins to be expressed as early as $150 \mathrm{msec}$ after presentation of target location (Messier \& Kalaska, 2000).

Although most data seem to emphasize a role of premotor areas in planning rather than in active memory, whether premotor tonic activity has a role in the representation of information in working memory remains in question. In most paradigms, premotor and prefrontal activity may appear contingent, but strong differences can appear with true comparisons and adapted behavioral tasks (di Pellegrino \& Wise, 1993b).

\section{THE SENSORY PATHWAYS}

\section{Dorsal Visual Pathway}

General properties. The dorsal visual stream (Figure 3) includes cortical areas MT, MST, PO, DP, VIP, LIP, and 7a (Felleman \& Van Essen, 1991; Ungerleider \& Mishkin, 1982). Receptive fields of neurons in these areas cover the visual periphery, with increasing size in successive stages of the pathway (Blatt, Andersen, \& Stoner, 1990; Komatsu \& Wurtz, 1988; Raiguel et al., 1997). The majority of neurons exhibit contralateral receptive fields, with bilateral fields common among neurons in area 7a, which, interestingly, often exclude the fovea (Motter \& Mountcastle, 1981). Neuronal responses in higher level areas are also increasingly modulated by cognitive factors such as selective attention and reward expectation (Cook \& Maunsell, 2002; Platt \& Glimcher, 1999; Treue \& Maunsell, 1996).

The hallmark of the dorsal visual pathway is the specialized neural circuitry for the analysis of visual spatial information and motion. Neurons in successive stages of the pathway respond to progressively more complex attributes, from the absolute direction of motion of a visual stimulus to parameters such as the radial expansion and contraction of a dynamic display, the location of its center of motion, and the speed of optic flow (Bremmer, Duhamel, Ben Hamed, \& Graf, 2002; Duffy \& Wurtz, 1991; Duhamel, Bremmer, Ben Hamed, \& Graf, 1997; Heuer \& Britten, 2004; Merchant, Battaglia-Mayer, \& Georgopoulos, 2001; Phinney \& Siegel, 2000; Steinmetz, Motter, Duffy, \& Mountcastle, 1987). This information is necessary for estimating the speed and heading
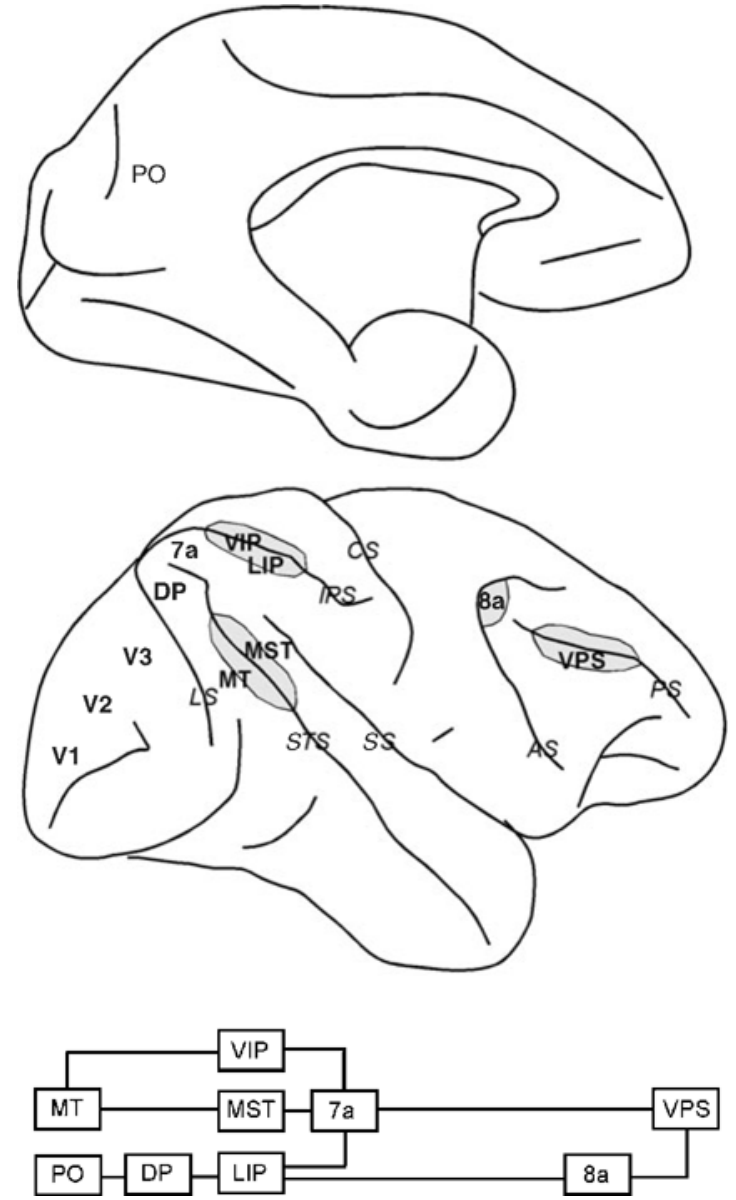

Figure 3. Dorsal visual pathway. Top diagram: medial view of the brain. Bottom diagram: simplified connectivity pattern between the areas of the dorsal visual pathways. Abbreviations of cortical areas: DP, dorsal parietal; LIP, lateral intraparietal; MST, medial superior temporal; MT, medial temporal; PO, parietal occipital; VIP, ventral intraparietal; VPS, ventral principal sulcal.

of motion and the trajectory of targets relative to the subject's own path. Even more abstract spatial information has been recently reported in the activity of area 7 a neurons, such as the direction of a continuous path in a visual maze (Crowe, Chafee, Averbeck, \& Georgopoulos, 2004).

The segregation of the cortical visual pathways into a dorsal and a ventral visual stream provides a powerful framework for the classification of neuronal properties, and it is tempting to interpret such a scheme as an extension of the magno- and parvocellular pathways of the lateral geniculate nucleus. However, it is clear that the two pathways are only relatively segregated, since they each share both magnocellular and parvocellular inputs (Ferrera, Nealey, \& Maunsell, 1992; Haenny, Maunsell, $\&$ Schiller, 1988) and areas across the two streams are anatomically connected to each other (Felleman \& Van Essen, 1991). In recent years, the functional dichotomy between the properties of neurons in the two streams has 
also been shown not to be absolute. It is now clear that posterior parietal neurons exhibit significant selectivity for stimulus attributes such as shape and color (Constantinidis \& Steinmetz, 2001a; Sereno \& Maunsell, 1998; Toth \& Assad, 2002). The selectivity may be further enhanced after training in a task requiring recognition of the stimulus attributes.

Modulation by extraretinal factors. Neurons encode selectively the locations and directions of stimuli with behavioral importance, such as those associated with potential rewards or stimuli that attract attention by virtue of their inherent salience (Bushnell, Goldberg, \& Robinson, 1981; Constantinidis \& Steinmetz, 2001a; Gottlieb, Kusunoki, \& Goldberg, 1998; Lynch, Mountcastle, Talbot, \& Yin, 1977). Similarly, neuronal activity reflects perceptual decisions about stimulus attributes, such as the perceived direction motion of a random dot display (Shadlen \& Newsome, 2001).

Neurons in the dorsal visual system discharge in response to inferred motion, involving no physical movement of a light source (e.g., when a moving stimulus briefly disappears behind an occluder; Assad \& Maunsell, 1995), and to apparent motion, an illusion created by the flashing of stationary stimuli at appropriate intervals (Merchant, Battaglia-Mayer, \& Georgopoulos, 2004; Newsome, Mikami, \& Wurtz, 1986). Dorsal pathway neurons also begin discharging in anticipation of a stimulus landing in their receptive field, due to a saccade (Duhamel, Colby, \& Goldberg, 1992). Conversely, neurons are silenced during the displacement on the retina of an otherwise stationary stimulus due to a saccade, or compensate for the relative movement of the stimulus by exhibiting reverse-direction selectivity during the eye movement (Thiele, Henning, Kubischik, \& Hoffmann, 2002). Neuronal responses are also modulated depending on the distance of a visual stimulus from the body and the part of the body on which a moving target is projected to land (Colby, Duhamel, \& Goldberg, 1993; Duhamel, Colby, \& Goldberg, 1998). Similarly, the position of the eyes in the orbit (angle of gaze) as well as the rotation of the head influence neuronal activity, interacting with the retinal position of a stimulus in a multiplicative function (Andersen, Essick, \& Siegel, 1985; Andersen \& Mountcastle, 1983; Brotchie, Andersen, Snyder, \& Goodman, 1995; Galletti, Battaglini, \& Fattori, 1995; Snyder, Grieve, Brotchie, \& Andersen, 1998). The combination of retinal, eye, and head positions can specify the absolute location of a stimulus in relation to the head or body, which in turn is necessary for the guidance and coordination of eye and limb movements. The posterior parietal cortex is anatomically connected with the superior colliculus, and populations of parietal neurons explicitly represent motor attributes of movements (Andersen, Snyder, Li, \& Stricanne, 1993; Mountcastle, Lynch, Georgopoulos, Sakata, \& Acuna, 1975; Snyder, Batista, \& Andersen, 1997). Microstimulation, particularly in area LIP, generates eye movements (Shibutani, Sakata, \& Hyvarinen, 1984). Reaching movements have been reported for adjoining parietal areas (Andersen, Snyder, Batista, Buneo, \& Cohen, 1998).

Memory-related properties. The posterior parietal cortex projects to the prefrontal cortex in a systematic manner: Projections from area LIP terminate mostly in the frontal eye field (area 8a), whereas area 7a projects mostly in the dorsal principal sulcal part of area 46 (Cavada \& Goldman-Rakic, 1989). The corresponding parietal and prefrontal areas exhibit very similar properties, and it seems safe to assume that prefrontal neurons exhibit the same type of location and motion selectivity as that described for posterior parietal neurons. Functional similarities between the two regions include memory-related activity. Indeed, neuronal discharges in areas LIP and 7a persist after the offset of transient visual stimuli, and it is tuned for their spatial locations (Andersen et al., 1987; Chafee \& Goldman-Rakic, 1998; Constantinidis \& Steinmetz, 1996; Gnadt \& Andersen, 1988; Quintana \& Fuster, 1992). Posterior parietal and dorsolateral prefrontal cortices are coactive during working memory tasks (Friedman \& Goldman-Rakic, 1994), and neuronal responses in the two areas are virtually indistinguishable, at least during the execution of an ODR task (Chafee \& GoldmanRakic, 1998). Neurons active during the delay period in both the prefrontal and parietal cortices can be grouped into two broad categories (see Figure 1B). For one population of neurons, the appearance of the visual stimulus elicits a phasic response, which is sustained after its termination or decays slowly, as would be expected for a working memory process. A second population of neurons begins to discharge only after the offset of the cue with an accelerating time course that peaks at about the time of the response, suggesting a prospective or anticipatory role (Quintana \& Fuster, 1992). Similar percentages of neurons display persistent activity with the same time courses in the prefrontal and parietal cortices.

Differences between the prefrontal and parietal areas have emerged only through the use of more complex tasks. Use of a spatial version of the delayed-matchingto-sample task, which requires subjects to remember the spatial location of a sample stimulus and ignore intervening, nonmatch stimuli, revealed that neurons in posterior parietal cortex encode the location of the most recent stimulus, whether it is the remembered sample or the behaviorally irrelevant nonmatch. Parietal neurons respond in a persistent fashion to the presentation of irrelevant stimuli in the receptive field (Constantinidis \& Steinmetz, 1996; Powell \& Goldberg, 2000) while ceasing to represent the sample stimulus. This is so even though the animal continues to retain the sample in memory and successfully completes the trial. Prefrontal neurons, on the other hand, encode the actively remembered sample; they continue to exhibit elevated levels of discharge following the presentation of a cue in the receptive field, even after the appearance of a behaviorally irrelevant stimulus out of the receptive field (di Pellegrino \& Wise, 1993a, 1993b).

Traces of memory-related activity have been further described in lower areas of the dorsal visual pathway. 
Neurons in area MT display continued activity shortly after the offset of the sensory stimulus, which typically does not survive for more than a few hundred milliseconds but which is weakly tuned for the direction of motion of a visual stimulus (Bisley, Zaksas, Droll, \& Pasternak, 2004). This brief, sustained activation is followed by a decrease in activity below that of the baseline. A similar memory-related modulation of neuronal activity has been reported in areas V3A and V1 (Nakamura \& Colby, 2000; Super, Spekreijse, \& Lamme, 2001). In these areas, neuronal activation typically decreases from the background when an animal is actively maintaining a stimulus in memory.

In addition to the persistent responses observed in the parietal cortex after the offset of a brief stimulus, a memory-related phenomenon has been described in terms of the firing rate of neurons to the match stimulus in the context of a delayed-matching-to-sample task. After monkeys are trained to recall the spatial location of a sample stimulus, a second presentation of the same stimulus, which constitutes a match, produces substantially decreased firing in the majority of neurons in area 7a (Constantinidis \& Steinmetz, 2001b; Steinmetz, Connor, Constantinidis, \& McLaughlin, 1994; Steinmetz \& Constantinidis, 1995). This effect has been interpreted as suggesting a role of the parietal cortex in redirecting attention to stimuli appearing away from the current locus of attention. It is impossible, however, to completely dissociate attention from working memory, and it is unclear whether diminished responses may play a role in the recall of a stimulus as being the match sought in the trial. A related phenomenon has to do with the novelty of a stimulus presentation. When a sample stimulus appears at a new, unpredictable spatial location, it produces a robust response. Subsequent presentations of the stimulus at the same location in a block of trials produce progressively diminished response (Steinmetz \& Constantinidis, 1995).

Recent experiments have led to the proposal that working memory in the parietal lobe may be dependent not only on deviations in the average firing rate of neurons but also on changes in their temporal pattern of responses. During a delayed response task, an increase in rhythmic firing was observed in the gamma frequency range (Pesaran, Pezaris, Sahani, Mitra, \& Andersen, 2002). However, a similar analysis in the prefrontal cortex failed to uncover significant rhythmicity, at least in the discharges of single neurons (Compte et al., 2003). The effect may be most evident in local field potential recordings, suggesting that temporal entrainment of activity may emerge in the pooled activity of a large number of neurons during the maintenance of working memory.

\section{Ventral Visual Pathway}

General properties. The ventral visual stream (Figure 4) includes area V4 and temporal areas alternatively known as TEO and TE or PIT, CIT, and AIT (posterior, central, and anterior inferior-temporal areas, respectively).

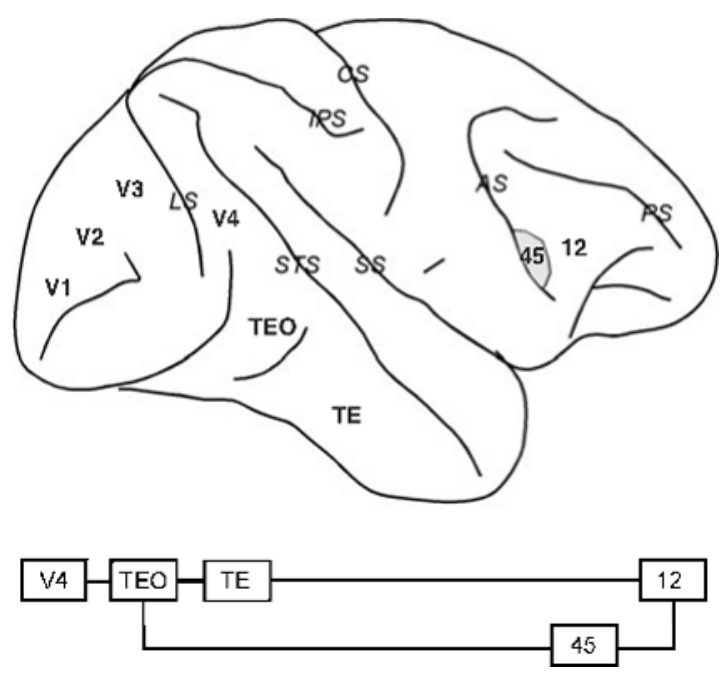

Figure 4. Ventral visual pathway. Conventions are the same as in Figure 2.

Receptive fields of neurons increase in size across the pathway, with bilateral receptive fields observed in AIT, which almost invariably include the fovea and most often display their peak response near the center of gaze (Gross, Bender, \& Gerstein, 1979; Gross, Rocha-Miranda, \& Bender, 1972; Schwartz, Desimone, Albright, \& Gross, 1983; Tovee, Rolls, \& Azzopardi, 1994). As is the case for the dorsal visual pathway, the responses of neurons in higher areas of the pathway are increasingly modulated by attention and other cognitive factors (Chelazzi, Duncan, Miller, \& Desimone, 1998; Luck, Chelazzi, Hillyard, \& Desimone, 1997; Moran \& Desimone, 1985; Richmond, Wurtz, \& Sato, 1983).

Neurons in the ventral visual pathway respond to progressively more complex stimulus features. Populations of neurons in area V4 are tuned to color and to geometric shape, defined by local stimulus features such as orientation, length, and curvature (Desimone, Schein, Moran, \& Ungerleider, 1985; Gallant, Connor, Rakshit, Lewis, \& Van Essen, 1996; Hinkle \& Connor, 2002; Pasupathy \& Connor, 2001; Zeki, 1978). On the other hand, inferior temporal (IT) neurons are highly selective for complex features of visual stimuli and may respond only to specific images or objects, such as faces (Desimone, Albright, Gross, \& Bruce, 1984; Fujita, Tanaka, Ito, \& Cheng, 1992; Gross et al., 1972; Tanaka, Saito, Fukada, \& Moriya, 1991). Furthermore, inferior temporal responses exhibit size and translation invariance: A neuron responds to its preferred object regardless of where it is presented within its receptive field and regardless of the size of the stimulus on the retina (Ito, Tamura, Fujita, \& Tanaka, 1995; Schwartz et al., 1983; Tovee et al., 1994). IT neurons also respond to a range of views of a 3-D object rotated in space (Logothetis \& Pauls, 1995; Logothetis, Pauls, \& Poggio, 1995). These properties are essential for object recognition, since the same object appearing at different viewing distances and positions in the visual 
field must elicit activity in the same population of neurons in order to be encoded consistently. However, the object invariance of IT response is not absolute; although IT receptive fields are large, they are finite. A neuron's preferred object will fail to elicit a response if it is presented entirely outside the receptive field boundaries. Even when the stimulus is presented within a neuron's receptive field, neuronal responses can vary significantly for different positions (DiCarlo \& Maunsell, 2003; Op De Beeck \& Vogels, 2000) and neurons typically respond to only a limited range of views of a rotated object (Logothetis \& Pauls, 1995). The relative selectivity of the neuron for different stimuli is generally preserved at each location.

Since the segregation of the dorsal and ventral pathways is only relative, it is no surprise that neurons in the ventral pathway would respond to spatial properties of stimuli. For example, V4 neurons respond to moving stimuli and display no lesser tuning for speed than MT neurons do (Cheng, Hasegawa, Saleem, \& Tanaka, 1994). Although early studies emphasized location invariance of IT neurons, recent experiments suggest that IT cortex may possess spatial selectivity, particularly for parafoveal stimuli. Bilateral receptive fields are frequent in IT cortex; however, some neurons do exhibit narrow receptive fields (on the order of $4^{\circ}$ ) that are distributed evenly around the fovea. Even among neurons with larger receptive fields, almost half respond best to a location within the central $4^{\circ}$ of vision other than the fovea (Op De Beeck \& Vogels, 2000). Similarly, IT neurons can exhibit strong spatial selectivity for stimuli within $1.5^{\circ}$ of the center of vision, at least after training in fine discrimination (DiCarlo \& Maunsell, 2003). These results suggest that IT neurons are capable of encoding the spatial locations of stimuli within a few degrees from the center of vision.

Modulation by extraretinal factors. Neuronal responses in IT cortex can be quite malleable. After monkeys are trained to group stimuli together and recognize them as belonging in the same group or category, neuronal responses often mirror the perceptual grouping. IT neurons respond to both stimuli of an associated pair, even when the two images were grouped arbitrarily and have no resemblance to each other (Messinger, Squire, Zola, \& Albright, 2001; Sakai \& Miyashita, 1991). Conversely, neurons may respond differentially to visually similar stimuli that have been grouped into different categories (Freedman, Riesenhuber, Poggio, \& Miller, 2003). Furthermore, neuronal responses are primarily modulated by the diagnostic features that were used to group stimuli into categories (Sigala \& Logothetis, 2002).

Responses of neurons in the ventral visual stream are greatly modulated by selective attention. Neuronal responses are generally higher to an attended stimulus, a stimulus appearing at an attended attention, or one exhibiting a feature for which the monkey is searching, such as color or orientation (Chelazzi, Miller, Duncan, \& Desimone, 1993; Haenny et al., 1988; Jagadeesh, Chelazzi, Mishkin, \& Desimone, 2001; Moran \& Desimone, 1985; Motter, 1994). The effect of spatial attention can be thought of as equivalent to a shrinking of the neuron's receptive field around the attended stimulus so that stimuli appearing away from the focus of attention fail to elicit an appreciable response (Moran \& Desimone, 1985; Richmond et al., 1983; Rolls, Aggelopoulos, \& Zheng, 2003). Even unattended stimuli can elicit stronger responses if they appear near the focus of attention (Connor, Gallant, Preddie, \& Van Essen, 1996; Connor, Preddie, Gallant, \& Van Essen, 1997). Like the effects of attention, binocular rivalry suggests that IT neurons selectively represent the image perceived by the subject under conditions of competition between two images presented separately to the two eyes (Sheinberg \& Logothetis, 1997).

Memory responses. The inferior temporal cortex is reciprocally connected to the ventral aspect of the prefrontal cortex. Connections generally maintain their anterior-posterior organization so that TEO projects mostly to the inferior limb of the arcuate sulcus (area 45), whereas TE targets primarily area 12 of the inferior convexity (Distler, Boussaoud, Desimone, \& Ungerleider, 1993; Kawamura \& Naito, 1984; Markowitsch, Emmans, Irle, Streicher, \& Preilowski, 1985; Webster, Bachevalier, \& Ungerleider, 1994). IT and prefrontal cortices share a number of physiological properties, including feature selectivity and modulation by factors such as categorization. They also both exhibit memory-related activation. IT neurons discharge in a persistent fashion after the offset of visual stimuli, and their activity encodes the features of the remembered stimulus (Fuster \& Jervey, 1981, 1982; Miller, Li, \& Desimone, 1993; Miyashita \& Chang, 1988; Nakamura \& Kubota, 1995; Naya, Yoshida, \& Miyashita, 2001). Neuronal activity during the delay period may remain fairly constant or accelerate in anticipation of a response or another behavioral event in the trial, as do prefrontal responses (Rainer \& Miller, 2002; Yakovlev, Fusi, Berman, \& Zohary, 1998).

Memory-related responses in IT cortex exhibit many intriguing parallels with those of the posterior parietal cortex. Persistent discharges of IT neurons are interrupted by nonmatching, distracting stimuli presented in the context of a delayed-matching-to-sample task (Miller et al., 1993). On the other hand, responses in the ventral prefrontal cortex represent the actively remembered sample (Miller, Erickson, \& Desimone, 1996). As is the case with the posterior parietal cortex, IT cortex appears to represent the remembered image of the most recent stimulus to appear in the physical world. IT neurons also exhibit match suppression and novelty effects. After presentation of a stimulus as a sample, the same stimulus produces reduced responses in the delayed-matching-tosample task when it appears as a match in comparison with when it appears as a nonmatch (Miller, Li, \& Desimone, 1991). Similarly, repetition of a stimulus presentation over several trials results in diminishing responses. Such changes in the mean firing rate related to the previous appearance of a stimulus over a few seconds or minutes may mediate some aspect of memory maintenance for these stimuli. 


\section{Somatosensory Pathway}

Somatosensory information (SI) is processed by the primary somatosensory cortex situated in the postcentral gyrus and relayed to the secondary (SII) and higher order somatosensory areas (Figure 5), including areas 5 and $7 \mathrm{~b}$ in the parietal lobe and the insular cortex (Ig). The ventral rim of area 46 is anatomically connected with parietal lobe regions, mostly $7 \mathrm{~b}$ (Cavada \& Goldman-Rakic, 1989). Similarly to the neurons of the visual cortex, somatosensory neurons at successive stages of the cortical hierarchy progressively extract more complex features of tactile stimuli, from the frequency of vibration to texture and shape (Phillips, Johnson, \& Hsiao, 1988). These neurons are also modulated by cognitive factors, such as directed attention, which produces more pronounced results at higher stages of the cortical hierarchy (Hsiao, O'Shaughnessy, \& Johnson, 1993).

Prefrontal cortical neurons have been shown to remain active after the presentation of vibratory stimuli that animals are required to remember for the purposes of a subsequent discrimination (Romo, Brody, Hernandez, \& Lemus, 1999). Furthermore, neuronal activity is graded

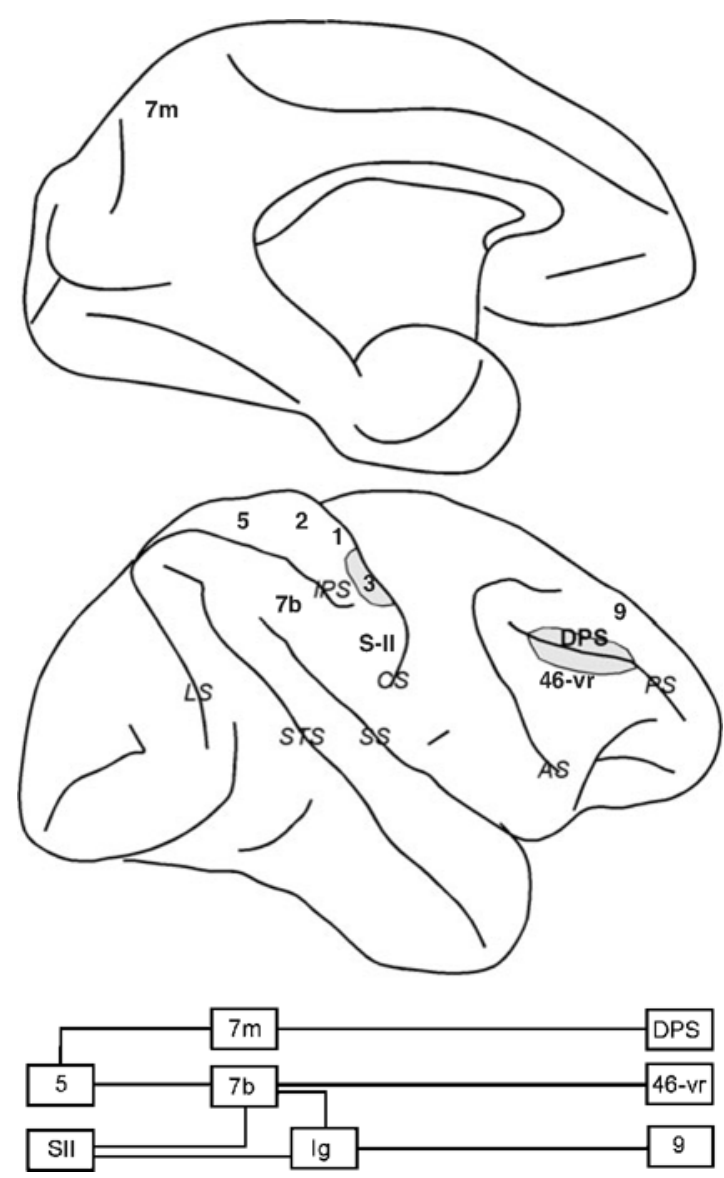

Figure 5. Somatosensory pathway. Abbreviations of cortical areas: Ig, insular cortex; DPS, dorsal principal sulcal; 46-vr, ventral rim of area 46. depending on the frequency of the vibratory stimulus. Activity in area 5 of the parietal lobe similarly persists after the offset of the stimulus and encodes haptic information (Koch \& Fuster, 1989). Parietal and prefrontal neurons exhibit similar time courses of activation during haptic memory, with different populations of neurons maintaining, increasing, or decreasing their firing rates in the delay interval.

Memory-related responses have been observed in lower areas of the somatosensory pathway. Neurons in SII typically discharge after the offset of the stimulus, but these responses quickly decay (Romo, Hernandez, Zainos, Lemus, \& Brody, 2002). A population of neurons exhibits sustained responses even in the primary somatosensory cortex (Zhou \& Fuster, 1996).

\section{Auditory Pathways}

The auditory cortex is organized in a central primary auditory cortex core, lining the ventral bank of the sylvian fissure and surrounded by a concentric circle of higher order auditory cortex known as the belt cortex (see Figure 6). A tertiary auditory area, the parabelt cortex, is located lateral to this belt. In recent years, two auditory pathways have been identified that are thought to process information about the identity of auditory stimuli and their locations in space, corresponding to the rostral and caudal belt and parabelt regions, respectively (Jones, Dell'Anna, Molinari, Rausell, \& Hashikawa, 1995; Kaas \& Hackett, 2000; Kosaki, Hashikawa, He, \& Jones, 1997; Rauschecker, Tian, \& Hauser, 1995). The two pathways terminate in discrete subdivisions of the frontal lobe; the rostral belt projects to the inferior convexity (areas 12 and 45), whereas the caudal belt cortex targets the caudal aspect of area 46 and area 8 (Hackett, Stepniewska, \& Kaas, 1999; Romanski, Bates, \& GoldmanRakic, 1999; Romanski, Tian, et al., 1999).

Prefrontal cortical neurons respond to auditory stimuli and exhibit sustained responses after stimulus offset (Azuma \& Suzuki, 1984; Bodner, Kroger, \& Fuster, 1996; Fuster, Bodner, \& Kroger, 2000; Romanski \& GoldmanRakic, 2002; Vaadia, Benson, Hienz, \& Goldstein, 1986). Delay period responses have been shown to be tuned to the characteristics of the sound, such as the spatial location of the sound source and the frequency of the auditory stimulus. Beyond the prefrontal cortex, neurons in area LIP of the posterior parietal cortex have been shown to be active during tasks requiring orienting to a remembered auditory target (Mazzoni, Bracewell, Barash, \& Andersen, 1996), but only if they have been trained to perform an eye-orienting task to auditory stimuli (Grunewald, Linden, \& Andersen, 1999). This selectivity may therefore be the result of eye-movement-planning information that has been associated with the auditory stimulus. Given the analogies in the organization of the auditory, visual, and somatosensory systems, it appears likely that neurons in the belt and parabelt cortices would display persistent, memory-related discharges, although no such responses have been reported to date. 

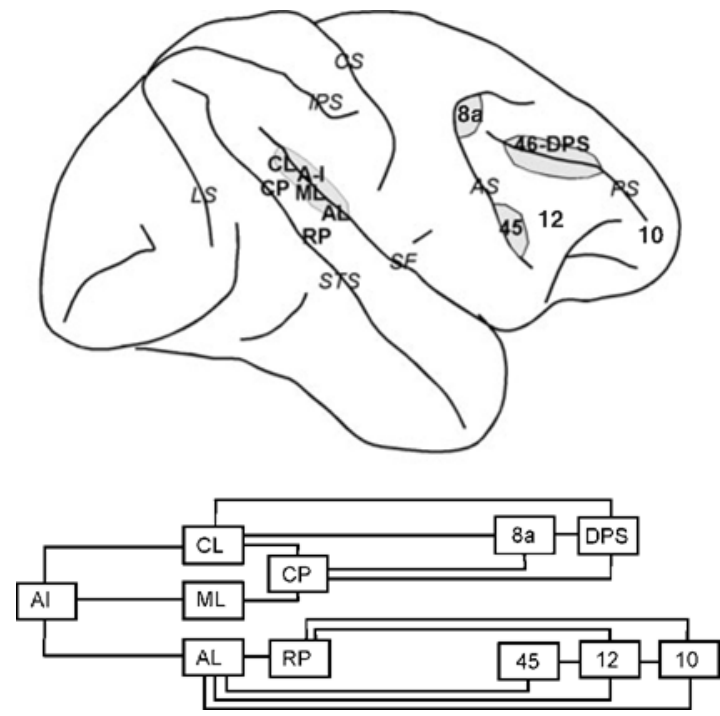

Figure 6. Auditory pathways. Abbreviations of cortical areas: AL, anterior lateral; CL, caudal lateral; CP, caudal parabelt; DPS, dorsal principal sulcal; ML, middle lateral; RP, rostral parabelt.

\section{Gustatory and Olfactory Pathways}

Gustatory cortical areas include the primary gustatory cortex in the postcentral gyrus and secondary areas, including the insula and precentral opercular areas. These project mostly to areas 12 and 13 of the orbitofrontal cortex (Cavada, Company, Tejedor, Cruz-Rizzolo, \& ReinosoSuárez, 2000). The same orbitofrontal areas are also targeted by the olfactory (pyriform) cortex. The entorhinal cortex also receives olfactory input directly from the olfactory bulb (Carmichael, Clugnet, \& Price, 1994). Although there are few neurophysiological studies in which gustatory and olfactory cues have been employed for tasks that engage working memory, examples of memoryrelated persistent responses specific for gustatory stimuli have been clearly described in the secondary gustatory and orbitofrontal cortices (Ifuku, Hirata, Nakamura, \& Ogawa, 2003).

\section{MEDIAL TEMPORAL CORTEX}

The cortex lining the medial temporal lobe is distinguished into perirhinal, entorhinal, and parahippocampal cortices. Although initially viewed as a singular system ancillary to the hippocampus, the areas comprising the medial temporal cortex now appear to have distinct functions and roles of unique importance. The perirhinal cortex (areas 35 and 36) receives extensive input from areas TE and TEO, and perirhinal neurons exhibit highly specialized visual object selectivity (Miller et al., 1993). In fact, perirhinal cortex is still often grouped with or classified as part of the inferior temporal cortex. In addition to visual information, however, the perirhinal cortex receives auditory and somatosensory inputs and perirhinal lesions produce deficits in tactile as well as visual recognition (Buffalo, Ramus, Squire, \& Zola, 2000). The discharge rate of perirhinal neurons is modulated by $\operatorname{cog}$ nitive factors such as reward expectation to a much greater extent than is that of neurons in the adjacent TE cortex (Liu \& Richmond, 2000). Perirhinal cortex also appears to be activated before TE in the delay interval of tasks that require recall of stimulus associations stored in long-term memory (Naya et al., 2001). The parahippocampal cortex (areas TH and TF) receives inputs from the posterior parietal cortex, the cingulate cortex, and the principal sulcus area of the prefrontal cortex. Due to this pattern of anatomical connections, the parahippocampal cortex has been thought to be involved in spatial memory. Indeed, recent neurophysiological investigation suggests that parahippocampal neurons exhibit mostly peripheral receptive fields and are less selective for visual object features than are neurons in the adjacent perirhinal cortex (Sato \& Nakamura, 2003). Both the perirhinal and parahippocampal cortices project to the entorhinal cortex, which constitutes the main input to the hippocampus.

The projections of the dorsal and ventral visual pathways into fairly distinct subdivisions of the medial temporal lobe, where they intermingle with spatial or objectselective signals from other sensory modalities, mirror the organization of the prefrontal cortex. Like neurons in the prefrontal cortex, entorhinal and perirhinal neurons exhibit sustained discharges following the presentation of memoranda (Erickson \& Desimone, 1999; Suzuki, Miller, \& Desimone, 1997), as do hippocampal neurons (Hampson, Pons, Stanford, \& Deadwyler, 2004). As is the case for the prefrontal cortex, entorhinal cortex demonstrates resistance to interference; when monkeys are required to remember the initial sample of a sequence of stimuli and disregard subsequent nonmatch stimuli, sustained discharges of entorhinal neurons represent the initial stimulus (Suzuki et al., 1997). Entorhinal and perirhinal neurons also exhibit differential responses to identical stimuli when they appear as match stimuli in a matching-tosample task, as well as familiarity and novelty effects (Holscher \& Rolls, 2002; Holscher, Rolls, \& Xiang, 2003; Miller et al., 1993; Suzuki et al., 1997).

\section{SUBCORTICAL STRUCTURES}

\section{Basal Ganglia}

The systems formed by the frontal cortex and the basal ganglia have been central to models designed to aid in the understanding of how the brain manages and controls routine and nonroutine behaviors (Shallice, 1988; Wise et al., 1996). In primates, the basal ganglia are formed by several substructures: the striatum, the globus pallidus (Gpe, Gpi), the substantia nigra (SNc, SNr), and the subthalamic nucleus. Within this network, the information flows from the striatum to the output nuclei schematically through two pathways (direct and indirect) that function in equilibrium (Hadj-Bouziane, Meunier, \& Boussaoud, 2003). The striatum, which is the main input structure of the basal ganglia, receives massive gluta- 
matergic cortical inputs that impose a relative functional compartmentalization on the striatum and the subsequent structures (Joel \& Weiner, 2000). Outputs via the $\mathrm{Gpi} / \mathrm{SNr}$ and the thalamus project back to cortical territories, creating cortico-striato-thalamo-cortical loops. For instance, various subdivisions of the PFC take part in parallel prefronto-striato-thalamo-cortical loops (Alexander, DeLong, \& Strick, 1986; Haber, Kunishio, Mizobuchi, \& Lynd-Balta, 1995; Middleton \& Strick, 2002; Selemon \& Goldman-Rakic, 1985). These loops form functional entities, which are more or less interconnected and may have a fundamental role in the control of motor output and in the flexibility and reinforcement of behavioral rules (Goldman-Rakic, Bates, \& Chafee, 1992; Joel \& Weiner, 2000; Passingham, 1993; Wise et al., 1996). A remarkable feature, which might be central to their adaptive properties, is that several nodes of these loops are targets of dopaminergic cells. The association of striatal and frontal dopamine input to learning and working memory is well known, and it is related to major prefrontal dysfunction in humans (Castner, Goldman-Rakic, \& Williams, 2004; Schultz, 2001; G. V. Williams \& Goldman-Rakic, 1995).

Thus, basal ganglia are positioned as a receptacle funneling and binding sensory, motor, and motivational cortical information (Hadj-Bouziane et al., 2003). Information about visuomotor association, sequential planning, and substantial sustained activity has been described in the basal ganglia and appears as evidence that the basal ganglia performs more than motor control (Hikosaka, Sakamoto, \& Usui, 1989a, 1989b; Kawagoe, Takikawa, \& Hikosaka, 1998; Kermadi \& Joseph, 1995; Wise et al., 1996). As in prefrontal cortex, visual and sustained activity during memory delay in the caudate nucleus reflects combined visual and motivational (reward expectation) information needed to perform working memory tasks (Kawagoe et al., 1998). Moreover, basal ganglia activation changes differentially during spatial and nonspatial working memory tasks (measured by 2-deoxyglucose imaging), reflecting the topographic ordering of prefrontal connections within the striatum. These results support a place for basal ganglia in a working memory network, which might be crucial to the cognitive dysfunction observed in Parkinson's disease (Dubois \& Pillon, 1997). Although its specific role may not be the maintenance of information, it might be to feed a prefrontaldependant maintenance system with associative and context-dependant information (Houk \& Wise, 1995).

\section{Thalamus}

The thalamus is a key structure in the corticostriato-thalamo-cortical loops. Its functional importance also relates to the direct corticothalamic systems which, combined to corticocortical connections, allow for collective computation and large-scale fast communication that may be at the base of cognitive binding (Houk \& Wise, 1995; Llinas, Leznik, \& Urbano, 2002; Llinas, Ribary, Contreras, \& Pedroarena, 1998). In this regard, Goldman-Rakic (1988) suggested that the thalamus would be a node through which functional subsystems (networks) can communicate and produce integrated behavior.

Studies of corticothalamic connectivity show that several thalamic nuclei connect with associative cortices. Among them, the MD nucleus and the medial nucleus of the pulvinar have mostly topographically organizedbut also some overlapping - connections with the prefrontal, premotor, anterior, and posterior cingulate and with the parietal and temporal cortices, thereby creating potential fast communications between several cortical territories (Giguere \& Goldman-Rakic, 1988; GoldmanRakic \& Porrino, 1985; Romanski, Giguere, Bates, \& Goldman-Rakic, 1997; Rouiller, Tanne, Moret, \& Boussaoud, 1999; Selemon \& Goldman-Rakic, 1988). This underlines a potentially important role for thalamic nuclei in cognitive functions, and particularly in working memory. Indeed, unit recordings in MD have shown typical activity during cognitive tasks (Fuster \& Alexander, 1973; Tanibuchi \& Goldman-Rakic, 2003; Watanabe \& Funahashi, 2004a). During a spatial delayed response task, MD tonic delay-related activities are similar to those found in lateral prefrontal or in parietal cortices, although globally and in comparison with these structures more MD unit activities seem to be devoted to the prospective or motor aspects of the task (Watanabe \& Funahashi, 2004a, 2004b). Observation of these similarities and differences reinforces the importance of further studies devoted to cognitive processes to analyze the contribution of the corticothalamic systems.

\section{AREAL SPECIALIZATION}

The manifestation of memory-related activity at multiple brain structures raises the question of how different brain areas are specialized in memory function. In particular, it is important to establish what role different brain areas play in the generation of persistent responses, and the type of information represented in memory by neuronal activity.

\section{Mechanisms of Persistent-Activity Generation}

The review of the sensory systems ultimately projecting to the prefrontal cortex reveals some important themes. Cortical areas at intermediate stages of sensory processing (e.g., MT, SII) exhibit activity after the termination of a stimulus decaying within a few hundred milliseconds but do not appear to possess the network infrastructure to sustain persistent activation for the entire delay interval of a memory task (Figure 7). Such ability is achieved at the end stages of the sensory pathways (e.g., area 7a, AIT). Still, in these areas delay period activity is disrupted by subsequent, irrelevant stimulus presentations. Full-blown, persistent representation of the stimulus actively held in memory appears to be a selective property of the prefrontal and entorhinal cortices.

Connections between areas within the sensory streams follow a hierarchical pattern, so that neurons in each area 


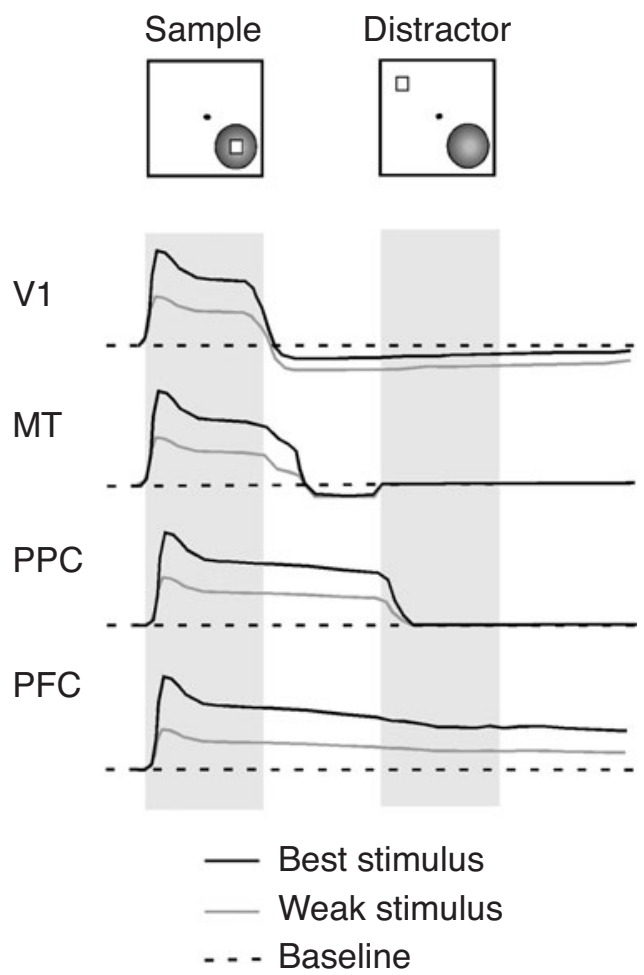

Figure 7. Manifestations of memory-related activity in successive visual cortical areas. Idealized neuronal responses are shown in response to two stimuli separated by a delay period: a sample that the subject is required to remember and a subsequent distractor. The black line represents responses to an optimal stimulus evoking the best response from the neuron. The gray line represents responses to a less effective stimulus evoking a moderate neuronal response. The dotted line represents the neurons' discharge rate baseline. Neuronal discharges in a small percentage of $\mathrm{V} 1$ neurons recede below the baseline during the active maintenance in memory of an optimal stimulus. Neurons in MT exhibit a short-lived persistent discharge that follows the disappearance of the stimulus. Their activity quickly returns to baseline, however. Neurons in posterior parietal cortex (PPC) - for example, in areas $7 \mathrm{a}$ and $\mathrm{LIP}$ - respond with sustained discharges in the delay period following the sample. However, these are terminated by the appearance of a distracting stimulus, outside the receptive field. Neurons in prefrontal cortex (PFC) - for example, in areas $8 \mathrm{a}$ and 46 - respond with sustained responses to the stimulus, which are not interrupted by the appearance of the distractor.

encode progressively more complex characteristics of a sensory stimulus. One might expect that the construction of memory activity would follow a similar pattern, with primarily sensory information transmitted from layers 2-3 of the sensory areas into layer 4 of the prefrontal cortex and transformed into delay period activity in the upper layers of the cortex. This is clearly not the case. Connections between prefrontal, temporal, and parietal areas are parallel, originating and terminating in layers 2-3 (Felleman \& Van Essen, 1991). Memory-related, persistent discharges are already present at the end stages of the sensory pathways, and neurons with sensory-driven, motor-related, or memory responses have been encountered at all layers of the prefrontal cortex. Since this pattern of connectivity deviates from the hierarchical model, it is not immediately obvious how persistent activity capable of surviving the interfering effect of distracting stimuli emerges in the prefrontal cortex.

Computational studies have offered insights into how cortical networks can sustain discharges in the absence of direct sensory stimulation and how distracting stimuli can be filtered during the active maintenance of memory (Compte, Brunel, Goldman-Rakic, \& Wang, 2000; Lisman, Fellous, \& Wang, 1998; X. J. Wang, Tegner, Constantinidis, \& Goldman-Rakic, 2004). Artificial networks can easily generate sustained discharges following transient sensory stimulation, if network units are densely and reciprocally connected (Compte et al., 2000). An action potential generated by a neuron is propagated to its synaptic targets, which in turn excite the original neuron, allowing for the activity to reverberate in the network provided it does not quickly die off. Computational models have demonstrated that persistent discharges exhibit increased signal-to-noise ratio in networks that incorporate dopamine inputs (Durstewitz, Seamans, \& Sejnowski, 2000). The effect is generally attributed to an enhanced NMDA conductance (Chen, Greengard, \& Yan, 2004; Seamans, Durstewitz, Christie, Stevens, \& Sejnowski, 2001; Yang \& Seamans, 1996), which in turn can facilitate persistent activity by virtue of its long time constant, leaving the postsynaptic neuron in a depolarized state for a longer interval (X. J. Wang, 2001). The prefrontal cortex, in contrast to its afferent inputs from the sensory pathways, receives a significant dopaminergic innervation from the ventral tegmental area that may render persistent activity particularly robust and less perturbed by distracting stimulation. Other prefrontal specializations that could have the same effect, such as a differential expression of NMDA receptors (Compte et al., 2000) or of specialized interneuron cell types (X. J. Wang et al., 2004), have also been suggested.

After the execution of a memory-guided response in a behavioral task, it is necessary to reset or switch off the contents of working memory for a new item to be stored in it. The source of such a reset signal also remains elusive. A possible mechanism that could achieve this goal is a nonselective burst of activity that could equally drive all neurons and destabilize persistent discharges (Compte et al., 2000). A burst of activity is evident in some prefrontal neurons after the end of a single trial or a sequence of actions, and such activity is not specific for the preceding motor movement (Fujii \& Graybiel, 2003; Funahashi et al., 1989). Goldman-Rakic et al. (1992) postulated that the MD nucleus of the thalamus constitutes the source of that signal; however, newer studies speak counter to this prediction, since most neurons activated near the response period of the task appear to discharge mainly before the response initiation (Tanibuchi $\&$ Goldman-Rakic, 2003). At this point, the source of the reset signal remains unclear. 


\section{Sensory Integration}

Areas that make up the working memory network may also be specialized in terms of their sensory integration. The prefrontal and entorhinal cortices receive inputs from all sensory modalities and are in a good position to integrate these inputs and represent cross-modal associations (Fuster et al., 2000). By some accounts, neurons throughout the prefrontal cortex are equally potent in representing the spatial information within $4^{\circ}$ of the fovea and features of visual memoranda, at least after behavioral training in a task that requires recall of both location and identity (Rao, Rainer, \& Miller, 1997). Contrary to this account, high featural selectivity for faces was encountered only in the inferior convexity of the prefrontal cortex, which is primarily innervated by the inferior temporal cortex ( Ó Scalaidhe, Wilson, \& GoldmanRakic, 1997; Wilson, Ó Scalaidhe, \& Goldman-Rakic, 1993). Newer results help resolve part of this discrepancy. It now appears that the ventral visual stream already possesses considerable spatial selectivity for stimuli within $4^{\circ}$ of the fovea, as was discussed above (DiCarlo \& Maunsell, 2003; Op De Beeck \& Vogels, 2000). Similarly, the posterior parietal cortex can be highly selective for the features of visual stimuli (Sereno \& Maunsell, 1998). Although the close proximity of the ventral- and dorsal-pathway recipient areas in the prefrontal cortex makes the integration of all types of information possible, it remains to be seen whether highly specialized information converges on the same neurons.

Persistent activity may not represent strictly the sensory attributes of stimuli, but more abstract information stored in memory as well. Functional specialization between areas in working memory networks may be evident in their ability to abstract information. In recent years, the discharges of prefrontal cortical neurons have been shown to represent rules, categories, and numerical quantities (Asaad et al., 2000; Freedman, Riesenhuber, Poggio, \& Miller, 2001; Nieder et al., 2002; Nieder \& Miller, 2003; Wallis, Anderson, et al., 2001; White \& Wise, 1999). However, it is now also evident that these are not unique prefrontal traits, since the inferior temporal and parietal cortices demonstrate similar properties (Freedman et al., 2003; Nieder \& Miller, 2004; Sigala \& Logothetis, 2002; Stoet \& Snyder, 2004).

A related proposal regarding the organization of the prefrontal cortex and working memory in general posits that distinct subsystems process different types of information, supervised by a central executive (Baddeley, 1992). The specialized systems can be viewed as storage components controlled and brought into focus by the central executive, which has limited capacity and cannot process all information available to the subsystems at the same time. It is tempting to attribute neural substrates for each component of working memory as specified by this model. It is fairly clear that working memory for different domains of information (e.g., auditory and visual) activates different networks. However, the functions attributed to the central executive appear to involve multi- ple brain areas, not restricted to the prefrontal cortex, and that even the prefrontal cortex is organized in segregated domains. In the words of Goldman-Rakic (1998):

Our view is that the central executive may be composed of multiple segregated special purpose processing domains rather than one central processor served by slave systems converging to a central processor; and that each specialized domain consists of local and extrinsic networks with sensory, mnemonic, motor and motivational control elements.

(pp. 97-98)

\section{Memory Systems for Action, Long-Term Consolidation, and Self-Monitoring}

Multisensory, memory-related discharges are present in at least two different cortical systems: the prefrontal cortex and the medial temporal lobe. This information may be used for different purposes in each of these systems. A working memory representation is necessary for the flexible selection of appropriate action, depending on the contingencies of the moment. The prefrontal cortex projects to cortical and subcortical motor structures and may guide the control of behavior depending on the contents of the working memory buffer. The medial temporal lobe has been thought to be more involved in the consolidation of memory. Cross-modal integration is necessary for placing information in context before storage in longterm memory. Finally, intelligent behavior requires a continuous monitoring of one's actions in relation to the internal state and values associated with the environment. Such a function appears to be carried out by the medial prefrontal and cingulate cortices, which require yet a third buffer of information. The distinct contents of each of these systems are generally not available to introspection. One of the challenges of neurosciences for the years ahead will be to reveal how information in distributed cortical systems is bound together into a unitary, conscious percept.

\section{REFERENCES}

Akkal, D., Bioulac, B., Audin, J., \& Burbaud, P. (2002). Comparison of neuronal activity in the rostral supplementary and cingulate motor areas during a task with cognitive and motor demands. European Journal of Neuroscience, 15, 887-904.

AleXANDER, G. E., DeLong, M. R., \& STRICK, P. L. (1986). Parallel organization of functionally segregated circuits linking basal ganglia and cortex. Annual Review of Neuroscience, 9, 357-381.

Amador, N., SchlaG-ReY, M., \& SchlaG, J. (2000). Reward-predicting and reward-detecting neuronal activity in the primate supplementary eye field. Journal of Neurophysiology, 84, 2166-2170.

Andersen, R. A., Essick, G. K., \& SiegeL, R. M. (1985). Encoding of spatial location by posterior parietal neurons. Science, 230, 456-458.

Andersen, R. A., Essick, G. K., \& Siegel, R. M. (1987). Neurons of area 7 activated by both visual stimuli and oculomotor behavior. $E x$ perimental Brain Research, 67, 316-322.

Andersen, R. A., \& Mountcastle, V. B. (1983). The influence of the angle of gaze upon the excitability of the light-sensitive neurons of the posterior parietal cortex. Journal of Neuroscience, 3, 532-548.

Andersen, R. A., Snyder, L. H., Batista, A. P., Buneo, C. A., \& Cohen, Y. E. (1998). Posterior parietal areas specialized for eye movements (LIP) and reach (PRR) using a common coordinate frame. Novartis Foundation Symposium, 218, 109-122. 
Andersen, R. A., Snyder, L. H., Li, C. S., \& Stricanne, B. (1993). Coordinate transformations in the representation of spatial information. Current Opinion in Neurobiology, 3, 171-176.

Asaad, W. F., Rainer, G., \& Miller, E. K. (2000). Task-specific neural activity in the primate prefrontal cortex. Journal of Neurophysiology, 84, 451-459.

AssAD, J. A., \& MAUNSELL, J. H. (1995). Neuronal correlates of inferred motion in primate posterior parietal cortex. Nature, 373,518 521

Azuma, M., \& Suzuki, H. (1984). Properties and distribution of auditory neurons in the dorsolateral prefrontal cortex of the alert monkey. Brain Research, 298, 343-346.

BADDELEY, A. (1992). Working memory. Science, 255, 556-559.

BARBAS, H. (2000). Connections underlying the synthesis of cognition, memory, and emotion in primate prefrontal cortices. Brain Research Bulletin, 52, 319-330.

Barbas, H., GhashghaeI, H., Dombrowski, S. M., \& Rempel-Clower, N. L. (1999). Medial prefrontal cortices are unified by common connections with superior temporal cortices and distinguished by input from memory-related areas in the rhesus monkey. Journal of Comparative Neurology, 410, 343-367.

BaRBAS, H., \& MESUlAM, M. M. (1985). Cortical afferent input to the principalis region of the rhesus monkey. Neuroscience, 15, 619-637.

Barbas, H., \& PANDYA, D. N. (1987). Architecture and frontal cortical connections of the premotor cortex (area 6) in the rhesus monkey. Journal of Comparative Neurology, 256, 211-228.

Bates, J. F., \& Goldman-RaKic, P. S. (1993). Prefrontal connections of medial motor areas in the rhesus monkey. Journal of Comparative Neurology, 336, 211-228.

BaXter, M. G., Parker, A., Lindner, C. C., Izquierdo, A. D., \& MurRay, E. A. (2000). Control of response selection by reinforcer value requires interaction of amygdala and orbital prefrontal cortex. Journal of Neuroscience, 20, 4311-4319.

Bechara, A., Damasio, H., Tranel, D., \& Anderson, S. W. (1998). Dissociation of working memory from decision making within the human prefrontal cortex. Journal of Neuroscience, 18, 428-437.

Bisley, J. W., Zaksas, D., Droll, J., \& PasternaK, T. (2004). Activity of neurons in cortical area MT during a memory for motion task. Journal of Neurophysiology, 91, 286-300.

BLATt, G. J., ANDERSEN, R. A., \& STONER, G. R. (1990). Visual receptive field organization and cortico-cortical connections of the lateral intraparietal area (area LIP) in the macaque. Journal of Comparative Neurology, 299, 421-445.

BoDNER, M., KROGER, J., \& Fuster, J. M. (1996). Auditory memory cells in dorsolateral prefrontal cortex. NeuroReport, 7, 1905-1908.

BoussaOud, D., \& WisE, S. P. (1993). Primate frontal cortex: Effects of stimulus and movement. Experimental Brain Research, 95, 28-40.

Bremmer, F., Duhamel, J. R., Ben Hamed, S., \& Graf, W. (2002). Heading encoding in the macaque ventral intraparietal area (VIP). European Journal of Neuroscience, 16, 1554-1568.

Brotchie, P. R., ANDERSEN, R. A., SNYDER, L. H., \& Goodman, S. J. (1995). Head position signals used by parietal neurons to encode locations of visual stimuli. Nature, 375, 232-235.

Buffalo, E. A., Ramus, S. J., SQuire, L. R., \& Zola, S. M. (2000). Perception and recognition memory in monkeys following lesions of area TE and perirhinal cortex. Learning \& Memory, 7, 375-382.

Bushnell, M. C., Goldberg, M. E., \& Robinson, D. L. (1981). Behavioral enhancement of visual responses in monkey cerebral cortex: I. Modulation in posterior parietal cortex related to selective visual attention. Journal of Neurophysiology, 46, 755-772.

Carmichael, S. T., Clugnet, M. C., \& PRice, J. L. (1994). Central olfactory connections in the macaque monkey. Journal of Comparative Neurology, 346, 403-434.

CASTNER, S. A., Goldman-RaKic, P. S., \& Williams, G. V. (2004). Animal models of working memory: Insights for targeting cognitive dysfunction in schizophrenia. Psychopharmacology, 174, 111-125.

Cavada, C., Company, T., Tejedor, J., CruZ-Rizzolo, R. J., \& ReinosoSuÁrez, F. (2000). The anatomical connections of the macaque monkey orbitofrontal cortex: A review. Cerebral Cortex, 10, 220-242.

Cavada, C., \& Goldman-Rakic, P. S. (1989). Posterior parietal cortex in rhesus monkey: II. Evidence for segregated corticocortical networks linking sensory and limbic areas with the frontal lobe. Journal of Comparative Neurology, 287, 422-445.

CHAFEe, M. V., \& GOLDMAN-RAKIC, P. S. (1998). Matching patterns of activity in primate prefrontal area $8 \mathrm{a}$ and parietal area 7ip neurons during a spatial working memory task. Journal of Neurophysiology, 79, 2919-2940.

Chelazzi, L., Duncan, J., Miller, E. K., \& Desimone, R. (1998). Responses of neurons in inferior temporal cortex during memory-guided visual search. Journal of Neurophysiology, 80, 2918-2940.

Chelazzi, L., Miller, E. K., Duncan, J., \& Desimone, R. (1993). A neural basis for visual search in inferior temporal cortex. Nature, $\mathbf{3 6 3}$, 345-347.

Chen, G., Greengard, P., \& Yan, Z. (2004). Potentiation of NMDA receptor currents by dopamine D1 receptors in prefrontal cortex. Proceedings of the National Academy of Sciences, 101, 2596-2600.

Cheng, K., Hasegawa, T., Saleem, K. S., \& TanaKa, K. (1994). Comparison of neuronal selectivity for stimulus speed, length, and contrast in the prestriate visual cortical areas V4 and MT of the macaque monkey. Journal of Neurophysiology, 71, 2269-2280.

Colby, C. L., Duhamel, J. R., \& GoldBERG, M. E. (1993). Ventral intraparietal area of the macaque: Anatomic location and visual response properties. Journal of Neurophysiology, 69, 902-914.

Compte, A., Brunel, N., GoldMAN-RAKIC, P. S., \& WANG, X. J. (2000). Synaptic mechanisms and network dynamics underlying spatial working memory in a cortical network model. Cerebral Cortex, 10, 910-923.

Compte, A., Constantinidis, C., Tegner, J., Raghavachari, S., Chafee, M. V., Goldman-Rakic, P. S., \& Wang, X. J. (2003). Temporally irregular mnemonic persistent activity in prefrontal neurons of monkeys during a delayed response task. Journal of Neurophysiology, 28, 3441-3454.

Connor, C. E., Gallant, J. L., Preddie, D. C., \& Van Essen, D. C. (1996). Responses in area V4 depend on the spatial relationship between stimulus and attention. Journal of Neurophysiology, 75, 13061308.

Connor, C. E., Preddie, D. C., Gallant, J. L., \& Van Essen, D. C. (1997). Spatial attention effects in macaque area V4. Journal of Neuroscience, 17, 3201-3214.

Constantinidis, C., Franowicz, M. N., \& Goldman-Rakic, P. S. (2001a). Coding specificity in cortical microcircuits: A multiple electrode analysis of primate prefrontal cortex. Journal of Neuroscience, 21, 3646-3655.

Constantinidis, C., Franowicz, M. N., \& Goldman-Rakic, P. S. (2001b). The sensory nature of mnemonic representation in the primate prefrontal cortex. Nature Neuroscience, 4, 311-316.

Constantinidis, C., \& Steinmetz, M. A. (1996). Neuronal activity in posterior parietal area 7 a during the delay periods of a spatial memory task. Journal of Neurophysiology, 76, 1352-1355.

Constantinidis, C., \& S Teinmetz, M. A. (2001a). Neuronal responses in area 7a to multiple stimulus displays: I. Neurons encode the location of the salient stimulus. Cerebral Cortex, 11, 581-591.

Constantinidis, C., \& Steinmetz, M. A. (2001b). Neuronal responses in area 7 a to multiple stimulus displays: II. Responses are suppressed at the cued location. Cerebral Cortex, 11, 592-597.

CoOK, E. P., \& MAunsell, J. H. (2002). Attentional modulation of behavioral performance and neuronal responses in middle temporal and ventral intraparietal areas of macaque monkey. Journal of Neuroscience, 22, 1994-2004.

Courtney, S. M., Ungerleider, L. G., Keil, K., \& Haxby, J. V. (1997). Transient and sustained activity in a distributed neural system for human working memory. Nature, 386, 608-611.

Crammond, D. J., \& KalasKa, J. F. (1994). Modulation of preparatory neuronal activity in dorsal premotor cortex due to stimulus-response compatibility. Journal of Neurophysiology, 71, 1281-1284.

Crowe, D. A., Chafee, M. V., Averbeck, B. B., \& Georgopoulos, A. P. (2004). Neural activity in primate parietal area 7a related to spatial analysis of visual mazes. Cerebral Cortex, 14, 23-34.

Desimone, R., Albright, T. D., Gross, C. G., \& Bruce, C. (1984). Stimulus-selective properties of inferior temporal neurons in the macaque. Journal of Neuroscience, 4, 2051-2062. 
Desimone, R., Schein, S. J., Moran, J., \& Ungerleider, L. G. (1985). Contour, color and shape analysis beyond the striate cortex. Vision Research, 25, 441-452.

DiCARLO, J. J., \& MAUNSELl, J. H. (2003). Anterior inferotemporal neurons of monkeys engaged in object recognition can be highly sensitive to object retinal position. Journal of Neurophysiology, $\mathbf{8 9}$, 3264-3278.

di Pellegrino, G., \& Wise, S. P. (1991). A neurophysiological comparison of three distinct regions of the primate frontal lobe. Brain, 114, 951-978.

DI Pellegrino, G., \& Wise, S. P. (1993a). Effects of attention on visuomotor activity in the premotor and prefrontal cortex of a primate. Somatosensory \& Motor Research, 10, 245-262.

di Pellegrino, G., \& Wise, S. P. (1993b). Visuospatial versus visuomotor activity in the premotor and prefrontal cortex of a primate. Journal of Neuroscience, 13, 1227-1243.

Distler, C., Boussaoud, D., Desimone, R., \& Ungerleider, L. G. (1993). Cortical connections of inferior temporal area TEO in macaque monkeys. Journal of Comparative Neurology, 334, 125-150.

Dubois, B., \& Pillon, B. (1997). Cognitive deficits in Parkinson's disease. Journal of Neurology, 244, 2-8.

DufFy, C. J., \& WuRTZ, R. H. (1991). Sensitivity of MST neurons to optic flow stimuli: I. A continuum of response selectivity to largefield stimuli. Journal of Neurophysiology, 65, 1329-1345.

Duhamel, J. R., Bremmer, F., Ben Hamed, S., \& Graf, W. (1997). Spatial invariance of visual receptive fields in parietal cortex neurons. Nature, 389, 845-848.

Duhamel, J. R., Colby, C. L., \& Goldberg, M. E. (1992). The updating of the representation of visual space in parietal cortex by intended eye movements. Science, 255, 90-92.

Duhamel, J. R., Colby, C. L., \& Goldberg, M. E. (1998). Ventral intraparietal area of the macaque: Congruent visual and somatic response properties. Journal of Neurophysiology, 79, 126-136.

DUM, R. P., \& STRICK, P. L. (1991). The origin of corticospinal projections from the premotor areas in the frontal lobe. Journal of Neuroscience, 11, 667-689.

DUM, R. P., \& STRICK, P. L. (1993). Cingulate motor areas. In M. Gabriel (Ed.), Neurobiology of cingulate cortex and limbic thalamus (pp. 415441). Boston: Birkhaüser.

Duncan, J., \& Owen, A. M. (2000). Common regions of the human frontal lobe recruited by diverse cognitive demands. Trends in $\mathrm{Neu}$ rosciences, $23,475-483$.

Durstewitz, D., Seamans, J. K., \& Sejnowski, T. J. (2000). Dopaminemediated stabilization of delay-period activity in a network model of prefrontal cortex. Journal of Neurophysiology, 83, 1733-1750.

ERICKSON, C. A., \& DESIMONE, R. (1999). Responses of macaque perirhinal neurons during and after visual stimulus association learning. Journal of Neuroscience, 19, 10404-10416.

Everling, S., Tinsley, C. J., Gaffan, D., \& Duncan, J. (2002). Filtering of neural signals by focused attention in the monkey prefrontal cortex. Nature Neuroscience, 5, 671-676.

Felleman, D. J., \& VAN Essen, D. C. (1991). Distributed hierarchical processing in the primate cerebral cortex. Cerebral Cortex, 1, 1-47.

Ferrera, V. P., Nealey, T. A., \& Maunsell, J. H. (1992). Mixed parvocellular and magnocellular geniculate signals in visual area V4. Nature, 358, 756-761.

Freedman, D. J., Riesenhuber, M., Poggio, T., \& Miller, E. K. (2001). Categorical representation of visual stimuli in the primate prefrontal cortex. Science, 291, 312-316.

Freedman, D. J., Riesenhuber, M., Poggio, T., \& Miller, E. K. (2002). Visual categorization and the primate prefrontal cortex: Neurophysiology and behavior. Journal of Neurophysiology, 88, 929941.

Freedman, D. J., Riesenhuber, M., Poggio, T., \& Miller, E. K. (2003). A comparison of primate prefrontal and inferior temporal cortices during visual categorization. Journal of Neuroscience, 23, 5235-5246

FRIEDMAN, H. R., \& GoldMAN-RAKIC, P. S. (1994). Coactivation of prefrontal cortex and inferior parietal cortex in working memory tasks revealed by 2 DG functional mapping in the rhesus monkey. Journal of Neuroscience, 14, 2775-2788.
Frith, C. D., Friston, K. J., Liddle, P. F., \& Frackowiak, R. S. (1991). Willed action and the prefrontal cortex in man: A study with PET. Proceedings of the Royal Society of London: Series B, 244, 241-246.

FuJII, N., \& GRAYBIEL, A. M. (2003). Representation of action sequence boundaries by macaque prefrontal cortical neurons. Science, $\mathbf{3 0 1}$, 1246-1249.

Fujita, I., TANaka, K., Ito, M., \& Cheng, K. (1992). Columns for visual features of objects in monkey inferotemporal cortex. Nature, 360, 343-346.

FunAHAShi, S., Bruce, C. J., \& Goldman-Rakic, P. S. (1989). Mnemonic coding of visual space in the monkey's dorsolateral prefrontal cortex. Journal of Neurophysiology, 61, 331-349.

Funahashi, S., Bruce, C. J., \& Goldman-RaKic, P. S. (1993). Dorsolateral prefrontal lesions and oculomotor delayed-response performance: Evidence for mnemonic "scotomas." Journal of Neuroscience, 13, 1479-1497.

FUSTER, J. M. (2001). The prefrontal cortex-an update: Time is of the essence. Neuron, 30, 319-333.

Fuster, J. M. (2003). Cortex and mind: Unifying cognition. Oxford: Oxford University Press.

Fuster, J. M., \& Alexander, G. E. (1971). Neuron activity related to short-term memory. Science, 173, 652-654.

Fuster, J. M., \& AleXANDER, G. E. (1973). Firing changes in cells of the nucleus medialis dorsalis associated with delayed response behavior. Brain Research, 61, 79-91.

Fuster, J. M., Bodner, M., \& Kroger, J. K. (2000). Cross-modal and cross-temporal association in neurons of frontal cortex. Nature, $\mathbf{4 0 5}$, 347-351.

FuSTER, J. M., \& JeRvey, J. P. (1981). Inferotemporal neurons distinguish and retain behaviorally relevant features of visual stimuli. $S c i-$ ence, 212, 952-955.

FUSTER, J. M., \& JERVEY, J. P. (1982). Neuronal firing in the inferotemporal cortex of the monkey in a visual memory task. Journal of Neuroscience, 2, 361-375.

Gallant, J. L., Connor, C. E., Rakshit, S., Lewis, J. W., \& Van EsSEN, D. C. (1996). Neural responses to polar, hyperbolic, and Cartesian gratings in area V4 of the macaque monkey. Journal of Neurophysiology, 76, 2718-2739.

Galletti, C., Battaglini, P. P., \& FAtTori, P. (1995). Eye position influence on the parieto-occipital area PO (V6) of the macaque monkey. European Journal of Neuroscience, 7, 2486-2501.

Giguere, M., \& GoldMAN-RAKIC, P. S. (1988). Mediodorsal nucleus: Areal, laminar, and tangential distribution of afferents and efferents in the frontal lobe of rhesus monkeys. Journal of Comparative Neurology, 277, 195-213.

GNADT, J. W., \& ANDERSEN, R. A. (1988). Memory related motor planning activity in posterior parietal cortex of macaque. Experimental Brain Research, 70, 216-220.

Godschalk, M., Mitz, A. R., van Duin, B., \& van der Burg, H. (1995). Somatotopy of monkey premotor cortex examined with microstimulation. Neuroscience Research, 23, 269-279.

Goldman-Rakic, P. S. (1988). Topography of cognition: Parallel distributed networks in primate association cortex. Annual Review of Neuroscience, 11, 137-156.

GoLDMAN-RAKIC, P. S. (1998). The prefrontal landscape: Implications of functional architecture for understanding human mentation and the central executive. In A. C. Roberts, T. W. Robbins, \& L. Weiskrantz (Eds.), The prefrontal cortex (pp. 87-102). Oxford: Oxford University Press.

Goldman-Rakic, P. S., Bates, J. F., \& Chafee, M. V. (1992). The prefrontal cortex and internally generated motor acts. Current Opinion in Neurobiology, 2, 830-835.

GoldMAN-RAKIC, P. S., \& PoRRINO, L. J. (1985). The primate mediodorsal (MD) nucleus and its projection to the frontal lobe. Journal of Comparative Neurology, 242, 535-560.

Gottlieb, J. P., KusunoKI, M., \& Goldberg, M. E. (1998). The representation of visual salience in monkey parietal cortex. Nature, $\mathbf{3 9 1}$, 481-484.

Gross, C. G., Bender, D. B., \& Gerstein, G. L. (1979). Activity of inferior temporal neurons in behaving monkeys. Neuropsychologia, $\mathbf{1 7}_{2}$ 215-229. 
Gross, C. G., Rocha-Miranda, C. E., \& Bender, D. B. (1972). Visual properties of neurons in inferotemporal cortex of the macaque. Journal of Neurophysiology, 35, 96-111.

GRUNEWALD, A., LiNDEN, J. F., \& ANDERSEN, R. A. (1999). Responses to auditory stimuli in macaque lateral intraparietal area: I. Effects of training. Journal of Neurophysiology, 82, 330-342.

Haber, S. N., Kunishio, K., Mizobuchi, M., \& Lynd-Balta, E. (1995). The orbital and medial prefrontal circuit through the primate basal ganglia. Journal of Neuroscience, 15, 4851-4867.

HaCKetT, T. A., StePNIEWSKA, I., \& KAAS, J. H. (1999). Prefrontal connections of the parabelt auditory cortex in macaque monkeys. Brain Research, 817, 45-58.

Hadj-Bouziane, F., Meunier, M., \& Boussaoud, D. (2003). Conditional visuo-motor learning in primates: A key role for the basal ganglia. Journal of Physiology, 97, 567-579.

Hadland, K. A., Rushworth, M. F., Gaffan, D., \& Passingham, R. E. (2003). The anterior cingulate and reward-guided selection of actions. Journal of Neurophysiology, 89, 1161-1164.

Haenny, P. E., Maunsell, J. H., \& SchILler, P. H. (1988). State dependent activity in monkey visual cortex: II. Retinal and extraretinal factors in V4. Experimental Brain Research, 69, 245-259.

Hampson, R. E., Pons, T. P., Stanford, T. R., \& Deadwyler, S. A. (2004). Categorization in the monkey hippocampus: A possible mechanism for encoding information into memory. Proceedings of the $\mathrm{Na}$ tional Academy of Sciences, 101, 3184-3189.

HatanaKa, N., ToKuno, H., Hamada, I., Inase, M., Ito, Y., ImaNishi, M., Hasegawa, N., AKazawa, T., Nambu, A., \& TaKada, M. (2003). Thalamocortical and intracortical connections of monkey cingulate motor areas. Journal of Comparative Neurology, 462, 121138.

Heuer, H. W., \& Britten, K. H. (2004). Optic flow signals in extrastriate area MST: Comparison of perceptual and neuronal sensitivity. Journal of Neurophysiology, 91, 1314-1326.

HiKosAKA, K., \& Watanabe, M. (2000). Delay activity of orbital and lateral prefrontal neurons of the monkey varying with different rewards. Cerebral Cortex, 10, 263-271.

Hikosaka, O., SaKamoto, M., \& Usui, S. (1989a). Functional properties of monkey caudate neurons: I. Activities related to saccadic eye movements. Journal of Neurophysiology, 61, 780-798.

Hikosaka, O., SAKamoto, M., \& Usui, S. (1989b). Functional properties of monkey caudate neurons: III. Activities related to expectation of target and reward. Journal of Neurophysiology, 61, 814-832.

HinKLE, D. A., \& CONNOR, C. E. (2002). Three-dimensional orientation tuning in macaque area V4. Nature Neuroscience, 5, 665-670.

Holscher, C., \& Rolls, E. T. (2002). Perirhinal cortex neuronal activity is actively related to working memory in the macaque. Neural Plasticity, 9, 41-51.

Holscher, C., Rolls, E. T., \& Xiang, J. (2003). Perirhinal cortex neuronal activity related to long-term familiarity memory in the macaque. European Journal of Neuroscience, 18, 2037-2046.

Houk, J. C., \& Wise, S. P. (1995). Distributed modular architectures linking basal ganglia, cerebellum, and cerebral cortex: Their role in planning and controlling action. Cerebral Cortex, 5, 95-110.

Hsiao, S. S., O'Shaughnessy, D. M., \& Johnson, K. O. (1993). Effects of selective attention on spatial form processing in monkey primary and secondary somatosensory cortex. Journal of Neurophysiology, 70, 444-447.

HuERta, M. F., Krubitzer, L. A., \& KaAs, J. H. (1986). Frontal eye field as defined by intracortical microstimulation in squirrel monkeys, owl monkeys, and macaque monkeys: I. Subcortical connections. Journal of Comparative Neurology, 253, 415-439.

Huerta, M. F., Krubitzer, L. A., \& KaAs, J. H. (1987). Frontal eye field as defined by intracortical microstimulation in squirrel monkeys, owl monkeys, and macaque monkeys: II. Cortical connections. Journal of Comparative Neurology, 265, 332-361.

IвA, M., \& SAWAGUCHI, T. (2003). Involvement of the dorsolateral prefrontal cortex of monkeys in visuospatial target selection. Journal of Neurophysiology, 89, 587-599.

IfUKU, H., HiRATA, S., NAKAMURA, T., \& Ogawa, H. (2003). Neuronal activities in the monkey primary and higher-order gustatory cortices during a taste discrimination delayed $\mathrm{GO} / \mathrm{NOGO}$ task and after reversal. Neuroscience Research, 47, 161-175.
Inoue, M., Mikami, A., Ando, I., \& Tsukada, H. (2004). Functional brain mapping of the macaque related to spatial working memory as revealed by PET. Cerebral Cortex, 14, 106-119.

Isomura, Y., Ito, Y., AKaZawa, T., Nambu, A., \& TAKada, M. (2003). Neural coding of "attention for action" and "response selection" in primate anterior cingulate cortex. Journal of Neuroscience, 23, 80028012.

Ito, M., Tamura, H., Fujita, I., \& Tanaka, K. (1995). Size and position invariance of neuronal responses in monkey inferotemporal cortex. Journal of Neurophysiology, 73, 218-226.

JACOBSEN, C. F. (1936). Studies of cerebral function in primates. Comparative Psychology Monogaphs, 13, 1-68.

Jagadeesh, B., Chelazzi, L., Mishkin, M., \& Desimone, R. (2001). Learning increases stimulus salience in anterior inferior temporal cortex of the macaque. Journal of Neurophysiology, 86, 290-303.

Joel, D., \& WeINER, I. (2000). The connections of the dopaminergic system with the striatum in rats and primates: An analysis with respect to the functional and compartmental organization of the striatum. Neuroscience, 96, 451-474.

Jones, E. G., Dell'AnNA, M. E., Molinari, M., Rausell, E., \& HashiKAWA, T. (1995). Subdivisions of macaque monkey auditory cortex revealed by calcium-binding protein immunoreactivity. Journal of Comparative Neurology, 362, 153-170.

Jonides, J., Smith, E. E., Koeppe, R. A., Awh, E., Minoshima, S., \& Mintun, M. A. (1993). Spatial working memory in humans as revealed by PET. Nature, 363, 623-625.

JoufFraIS, C., \& BoUSSAOUD, D. (1999). Neuronal activity related to eye-hand coordination in the primate premotor cortex. Experimental Brain Research, 128, 205-209.

KAAS, J. H., \& HACKETT, T. A. (2000). Subdivisions of auditory cortex and processing streams in primates. Proceedings of the National Academy of Sciences, 97, 11793-11799.

KaWAGOE, R., TAKIKaWA, Y., \& HikosaKa, O. (1998). Expectation of reward modulates cognitive signals in the basal ganglia. Nature Neuroscience, 1, 411-416.

KAWAMURA, K., \& NAITO, J. (1984). Corticocortical projections to the prefrontal cortex in the rhesus monkey investigated with horseradish peroxidase techniques. Neuroscience Research, 1, 89-103.

Kermadi, I., \& JosePH, J. P. (1995). Activity in the caudate nucleus of monkey during spatial sequencing. Journal of Neurophysiology, $\mathbf{7 4}_{2}$ 911-933.

Koch, C., \& Fuster, J. M. (1989). Unit activity in monkey parietal cortex related to haptic perception and temporary memory. Experimental Brain Research, 76, 292-306.

KoECHLIN, E., Ody, C., \& KouneIHer, F. (2003). The architecture of cognitive control in the human prefrontal cortex. Science, 302, 11811185.

Komatsu, H., \& Wurtz, R. H. (1988). Relation of cortical areas MT and MST to pursuit eye movements: I. Localization and visual properties of neurons. Journal of Neurophysiology, 60, 580-603.

Kosaki, H., Hashikawa, T., He, J., \& Jones, E. G. (1997). Tonotopic organization of auditory cortical fields delineated by parvalbumin immunoreactivity in macaque monkeys. Journal of Comparative Neurology, 386, 304-316.

KoSKI, L., \& PAUS, T. (2000). Functional connectivity of the anterior cingulate cortex within the human frontal lobe: A brain-mapping meta-analysis. Experimental Brain Research, 133, 55-65.

Kritzer, M. F., \& GoldMAN-RAKIC, P. S. (1995). Intrinsic circuit organization of the major layers and sublayers of the dorsolateral prefrontal cortex in the rhesus monkey. Journal of Comparative Neurology, 359, 131-143.

LEON, M. L., \& SHADLEN, M. N. (1999). Effect of expected reward magnitude on the response of neurons in the dorsolateral prefrontal cortex of the macaque. Neuron, 24, 415-425.

Lisman, J. E., Fellous, J. M., \& WANG, X. J. (1998). A role for NMDAreceptor channels in working memory. Nature Neuroscience, $\mathbf{1}, 273$ 275

LiU, Z., \& Richmond, B. J. (2000). Response differences in monkey TE and perirhinal cortex: Stimulus association related to reward schedules. Journal of Neurophysiology, 83, 1677-1692.

Llinas, R. R., LEZNIK, E., \& URbano, F. J. (2002). Temporal binding via cortical coincidence detection of specific and nonspecific thala- 
mocortical inputs: A voltage-dependent dye-imaging study in mouse brain slices. Proceedings of the National Academy of Sciences, $\mathbf{9 9}$, 449-454.

Llinas, R. R., Ribary, U., Contreras, D., \& Pedroarena, C. (1998). The neuronal basis for consciousness. Philosophical Transactions of the Royal Society of London: Series B, 353, 1841-1849.

Logothetis, N. K., \& Pauls, J. (1995). Psychophysical and physiological evidence for viewer-centered object representations in the primate. Cerebral Cortex, 5, 270-288.

Logothetis, N. K., Pauls, J., \& Poggio, T. (1995). Shape representation in the inferior temporal cortex of monkeys. Current Biology, $\mathbf{5}_{2}$ 552-563.

Lu, M. T., Preston, J. B., \& Strick, P. L. (1994). Interconnections between the prefrontal cortex and the premotor areas in the frontal lobe. Journal of Comparative Neurology, 341, 375-392.

LuCK, S. J., Chelazzi, L., Hillyard, S. A., \& Desimone, R. (1997). Neural mechanisms of spatial selective attention in areas V1, V2, and V4 of macaque visual cortex. Journal of Neurophysiology, 77, 2442.

Luppino, G., Matelli, M., Camarda, R. M., Gallese, V., \& RizzoLATTI, G. (1991). Multiple representations of body movements in mesial area 6 and the adjacent cingulate cortex: An intracortical microstimulation study in the macaque monkey. Journal of Comparative Neurology, 311, 463-482.

Lynch, J. C., Mountcastle, V. B., Talbot, W. H., \& Yin, T. C. (1977). Parietal lobe mechanisms for directed visual attention. Journal of Neurophysiology, 40, 362-389.

MacDonald, A. W., III, Cohen, J. D., Stenger, V. A., \& Carter, C. S. (2000). Dissociating the role of the dorsolateral prefrontal and anterior cingulate cortex in cognitive control. Science, 288, 1835-1838.

Markowitsch, H. J., Emmans, D., Irle, E., Streicher, M., \& PreiLOWSKI, B. (1985). Cortical and subcortical afferent connections of the primate's temporal pole: A study of rhesus monkeys, squirrel monkeys, and marmosets. Journal of Comparative Neurology, 242, 425-458.

Matelli, M., Luppino, G., \& Rizzolatti, G. (1991). Architecture of superior and mesial area 6 and the adjacent cingulate cortex in the macaque monkey. Journal of Comparative Neurology, 311, 445-462.

Matsumoto, K., SuzuKi, W., \& TanaKa, K. (2003). Neuronal correlates of goal-based motor selection in the prefrontal cortex. Science, 301, 229-232.

MaZzoni, P., Bracewell, R. M., Barash, S., \& Andersen, R. A. (1996). Spatially tuned auditory responses in area LIP of macaques performing delayed memory saccades to acoustic targets. Journal of Neurophysiology, 75, 1233-1241.

MCGuire, P. K., BATES, J. F., \& Goldman-RAKic, P. S. (1991). Interhemispheric integration: I. Symmetry and convergence of the corticocortical connections of the left and the right principal sulcus (PS) and the left and the right supplementary motor area (SMA) in the rhesus monkey. Cerebral Cortex, 1, 390-407.

Merchant, H., Battaglia-Mayer, A., \& Georgopoulos, A. P. (2001). Effects of optic flow in motor cortex and area 7a. Journal of Neurophysiology, 86, 1937-1954.

Merchant, H., Battaglia-Mayer, A., \& Georgopoulos, A. P. (2004). Neural responses in motor cortex and area $7 \mathrm{a}$ to real and apparent motion. Experimental Brain Research, 154, 291-307.

Messier, J., \& KalasKa, J. F. (2000). Covariation of primate dorsal premotor cell activity with direction and amplitude during a memorizeddelay reaching task. Journal of Neurophysiology, 84, 152-165.

Messinger, A., Squire, L. R., Zola, S. M., \& Albright, T. D. (2001). Neuronal representations of stimulus associations develop in the temporal lobe during learning. Proceedings of the National Academy of Sciences, 98, 12239-12244.

MeUnier, M., Bachevalier, J., \& Mishin, M. (1997). Effects of orbital frontal and anterior cingulate lesions on object and spatial memory in rhesus monkeys. Neuropsychologia, 35, 999-1015.

Middleton, F. A., \& Strick, P. L. (2002). Basal-ganglia "projections" to the prefrontal cortex of the primate. Cerebral Cortex, 12, 926-935.

Miller, E. K., \& CoHEN, J. D. (2001). An integrative theory of prefrontal cortex function. Annual Review of Neuroscience, 24, 167-202.

Miller, E. K., Erickson, C. A., \& Desimone, R. (1996). Neural mechanisms of visual working memory in prefrontal cortex of the macaque. Journal of Neuroscience, 16, 5154-5167.
Miller, E. K., Li, L., \& Desimone, R. (1991). A neural mechanism for working and recognition memory in inferior temporal cortex. Science, 254, 1377-1379.

Miller, E. K., LI, L., \& Desimone, R. (1993). Activity of neurons in anterior inferior temporal cortex during a short-term memory task. Journal of Neuroscience, 13, 1460-1478.

MiLner, B. (1963). Effects of different brain lesions on card sorting. Archives of Neurology, 9, 100-110.

Mitz, A. R., \& Wise, S. P. (1987). The somatotopic organization of the supplementary motor area: Intracortical microstimulation mapping. Journal of Neuroscience, 7, 1010-1021.

MiYASHITA, Y., \& ChANG, H. S. (1988). Neuronal correlate of pictorial short-term memory in the primate temporal cortex. Nature, 331, 6870 .

MoRAn, J., \& Desimone, R. (1985). Selective attention gates visual processing in the extrastriate cortex. Science, 229, 782-784.

MotTER, B. C. (1994). Neural correlates of attentive selection for color or luminance in extrastriate area V4. Journal of Neuroscience, $\mathbf{1 4}$, 2178-2189

Motter, B. C., \& Mountcastle, V. B. (1981). The functional properties of the light-sensitive neurons of the posterior parietal cortex studied in waking monkeys: Foveal sparing and opponent vector organization. Journal of Neuroscience, 1, 3-26.

Mountcastle, V. B., Lynch, J. C., Georgopoulos, A., Sakata, H., \& ACUNA, C. (1975). Posterior parietal association cortex of the monkey: Command functions for operations within extrapersonal space. Journal of Neurophysiology, 38, 871-908.

NaKamura, K., \& Colby, C. L. (2000). Visual, saccade-related, and cognitive activation of single neurons in monkey extrastriate area V3A. Journal of Neurophysiology, 84, 677-692.

NAKAmURA, K., \& KubOTA, K. (1995). Mnemonic firing of neurons in the monkey temporal pole during a visual recognition memory task. Journal of Neurophysiology, 74, 162-178.

NAKAMURA, K., SAKAI, K., \& HIKOSAKA, O. (1998). Neuronal activity in medial frontal cortex during learning of sequential procedures. Journal of Neurophysiology, 80, 2671-2687.

NAYA, Y., Yoshida, M., \& MiYAshita, Y. (2001). Backward spreading of memory-retrieval signal in the primate temporal cortex. Science, 291, 661-664.

Newsome, W. T., Mikami, A., \& Wurtz, R. H. (1986). Motion selectivity in macaque visual cortex: III. Psychophysics and physiology of apparent motion. Journal of Neurophysiology, 55, 1340-1351.

Nieder, A., Freedman, D. J., \& Miller, E. K. (2002). Representation of the quantity of visual items in the primate prefrontal cortex. Science, 297, 1708-1711.

NiEDER, A., \& Miller, E. K. (2003). Coding of cognitive magnitude: Compressed scaling of numerical information in the primate prefrontal cortex. Neuron, 37, 149-157.

Nieder, A., \& Miller, E. K. (2004). A parieto-frontal network for visual numerical information in the monkey. Proceedings of the $\mathrm{Na}$ tional Academy of Sciences, 101, 7457-7462.

NIKI, H., \& WATANABE, M. (1976). Cingulate unit activity and delayed response. Brain Research, 110, 381-386.

Olson, C. R., \& GetTNER, S. N. (1995). Object-centered direction selectivity in the macaque supplementary eye field. Science, 269, 985988.

Op De Beeck, H., \& Vogels, R. (2000). Spatial sensitivity of macaque inferior temporal neurons. Journal of Comparative Neurology, $\mathbf{4 2 6}$, 505-518.

Ó Scalaidhe, S., Wilson, F. A., \& Goldman-Rakic, P. S. (1997). Areal segregation of face-processing neurons in prefrontal cortex. Science, 278, 1135-1138.

PaSSINGHA M, R. (1993). The frontal lobes and voluntary action. Oxford: Oxford University Press.

Pasupathy, A., \& ConNor, C. E. (2001). Shape representation in area V4: Position-specific tuning for boundary conformation. Journal of Neurophysiology, 86, 2505-2519.

PaUS, T. (2001). Primate anterior cingulate cortex: Where motor control, drive and cognition interface. Nature Reviews Neuroscience, 2, 417-424.

Paus, T., Petrides, M., Evans, A. C., \& Meyer, E. (1993). Role of the human anterior cingulate cortex in the control of oculomotor, man- 
ual, and speech responses: A positron emission tomography study. Journal of Neurophysiology, 70, 453-469.

Pesaran, B., Pezaris, J. S., Sahani, M., Mitra, P. P., \& Andersen, R. A. (2002). Temporal structure in neuronal activity during working memory in macaque parietal cortex. Nature Neuroscience, $\mathbf{5}, 805$ 811.

Petrides, M. (2000). The role of the mid-dorsolateral prefrontal cortex in working memory. Experimental Brain Research, 133, 44-54.

Phillips, J. R., Johnson, K. O., \& HsiaO, S. S. (1988). Spatial pattern representation and transformation in monkey somatosensory cortex. Proceedings of the National Academy of Sciences, 85, 1317-1321.

Phinney, R. E., \& Siegel, R. M. (2000). Speed selectivity for optic flow in area $7 \mathrm{a}$ of the behaving macaque. Cerebral Cortex, 10, 413421.

Platt, M. L., \& Glimcher, P. W. (1999). Neural correlates of decision variables in parietal cortex. Nature, 400, 233-238.

Posner, M. I., \& DiGirolamo, G. J. (1998). Executive attention: Conflict, target detection and cognitive control. In R. Parasuraman (Ed.), The attentive brain (pp. 401-423). Cambridge, MA: MIT Press.

Powell, K. D., \& GoldBerg, M. E. (2000). Response of neurons in the lateral intraparietal area to a distractor flashed during the delay period of a memory-guided saccade. Journal of Neurophysiology, 84, 301310

Preuss, T. M., \& Goldman-Rakic, P. S. (1991). Architectonics of the parietal and temporal association cortex in the strepsirhine primate Galago compared to the anthropoid primate Macaca. Journal of Comparative Neurology, 310, 475-506.

PROCYK, E., \& JOSEPH, J. P. (2001). Characterization of serial order encoding in the monkey anterior cingulate sulcus. European Journal of Neuroscience, 14, 1041-1046.

ProcyK, E., TANAKA, Y. L., \& JOSEPH, J. P. (2000). Anterior cingulate activity during routine and non-routine sequential behaviors in macaques. Nature Neuroscience, 3, 502-508.

PuCAK, M. L., LeVITT, J. B., LUND, J. S., \& Lewis, D. A. (1996). Patterns of intrinsic and associational circuitry in monkey prefrontal cortex. Journal of Comparative Neurology, 376, 614-630.

QuintAnA, J., \& Fuster, J. M. (1992). Mnemonic and predictive functions of cortical neurons in a memory task. NeuroReport, 3, 721-724.

Raiguel, S., Van Hulle, M. M., Xiao, D. K., Marcar, V. L., Lagae, L., \& Orban, G. A. (1997). Size and shape of receptive fields in the medial superior temporal area (MST) of the macaque. NeuroReport, $\mathbf{8}$, 2803-2808.

Rainer, G., AsaAd, W. F., \& Miller, E. K. (1998). Selective representation of relevant information by neurons in the primate prefrontal cortex. Nature, 393, 577-579.

RAINER, G., \& MILLER, E. K. (2002). Timecourse of object-related neural activity in the primate prefrontal cortex during a short-term memory task. European Journal of Neuroscience, 15, 1244-1254.

RaO, S. C., Rainer, G., \& Miller, E. K. (1997). Integration of what and where in the primate prefrontal cortex. Science, 276, 821-824.

Rauschecker, J. P., Tian, B., \& Hauser, M. (1995). Processing of complex sounds in the macaque nonprimary auditory cortex. Science, 268, 111-114.

RICHMOND, B. J., WuRTz, R. H., \& SATo, T. (1983). Visual responses of inferior temporal neurons in awake rhesus monkey. Journal of Neurophysiology, 50, 1415-1432.

Rizzolatti, G., \& LuPPINO, G. (2001). The cortical motor system. Neuron, 31, 889-901.

RoLLS, E. T. (2002). The functions of the orbitofrontal cortex. In R. T. Knight (Ed.), Principles of frontal lobe function (pp. 354-375). Oxford: Oxford University Press.

Rolls, E. T., Aggelopoulos, N. C., \& Zheng, F. (2003). The receptive fields of inferior temporal cortex neurons in natural scenes. Journal of Neuroscience, 23, 339-348.

Romanski, L. M., Bates, J. F., \& Goldman-Rakic, P. S. (1999). Auditory belt and parabelt projections to the prefrontal cortex in the rhesus monkey. Journal of Comparative Neurology, 403, 141-157.

Romanski, L. M., Giguere, M., BATes, J. F., \& GolDMAN-RAKIC, P. S. (1997). Topographic organization of medial pulvinar connections with the prefrontal cortex in the rhesus monkey. Journal of Comparative Neurology, 379, 313-332.
RomansKi, L. M., \& Goldman-RAKIC, P. S. (2002). An auditory domain in primate prefrontal cortex. Nature Neuroscience, 5, 15-16.

Romanski, L. M., Tian, B., Fritz, J., MishKin, M., Goldman-Rakic, P. S., \& RAuscheckeR, J. P. (1999). Dual streams of auditory afferents target multiple domains in the primate prefrontal cortex. Nature Neuroscience, 2, 1131-1136.

Romo, R., Brody, C. D., Hernandez, A., \& Lemus, L. (1999). Neuronal correlates of parametric working memory in the prefrontal cortex. Nature, 399, 470-473.

Romo, R., Hernandez, A., Zainos, A., Lemus, L., \& Brody, C. D. (2002). Neuronal correlates of decision-making in secondary somatosensory cortex. Nature Neuroscience, 5, 1217-1225.

Rosenkilde, C. E., BAUER, R. H., \& Fuster, J. M. (1981). Single cell activity in ventral prefrontal cortex of behaving monkeys. Brain Research, 209, 375-394.

Rouiller, E. M., TANNe, J., Moret, V., \& Boussaoud, D. (1999). Origin of thalamic inputs to the primary, premotor, and supplementary motor cortical areas and to area 46 in macaque monkeys: A multiple retrograde tracing study. Journal of Comparative Neurology, 409 , 131-152.

Rushworth, M. F., Hadland, K. A., Gaffan, D., \& Passingham, R. E. (2003). The effect of cingulate cortex lesions on task switching and working memory. Journal of Cognitive Neuroscience, 15, 338353.

Russo, G. S., \& BRUCE, C. J. (1996). Neurons in the supplementary eye field of rhesus monkeys code visual targets and saccadic eye movements in an oculocentric coordinate system. Journal of Neurophysiology, 76, 825-848.

SAKAI, K., \& MiYASHITA, Y. (1991). Neural organization for the longterm memory of paired associates. Nature, 354, 152-155.

Salinas, E. (2004). Fast remapping of sensory stimuli onto motor actions on the basis of contextual modulation. Journal of Neuroscience, 24, 1113-1118.

SATO, N., \& NAKAMURA, K. (2003). Visual response properties of neurons in the parahippocampal cortex of monkeys. Journal of Neurophysiology, 90, 876-886.

SAWAGUCHI, T., \& GOLDMAN-RAKIC, P. S. (1991). D1 dopamine receptors in prefrontal cortex: Involvement in working memory. Science, 251, 947-950.

SAWAGUCHI, T., \& Goldman-RaKic, P. S. (1994). The role of D1dopamine receptor in working memory: Local injections of dopamine antagonists into the prefrontal cortex of rhesus monkeys performing an oculomotor delayed-response task. Journal of Neurophysiology, 71, 515-528.

ScHLAG, J., \& Schlag-REY, M. (1987). Evidence for a supplementary eye field. Journal of Neurophysiology, 57, 179-200.

Schlag-Rey, M., Amador, N., SANCHeZ, H., \& SchlaG, J. (1997). Antisaccade performance predicted by neuronal activity in the supplementary eye field. Nature, 390, 398-401.

Schultz, W. (2001). Reward signaling by dopamine neurons. Neuroscientist, 7, 293-302.

Schwartz, E. L., Desimone, R., Albright, T. D., \& Gross, C. G. (1983). Shape recognition and inferior temporal neurons. Proceedings of the National Academy of Sciences, 80, 5776-5778.

Seamans, J. K., Durstewitz, D., Christie, B. R., Stevens, C. F., \& SEJNOWSKI, T. J. (2001). Dopamine D1/D5 receptor modulation of excitatory synaptic inputs to layer V prefrontal cortex neurons. Proceedings of the National Academy of Sciences, 98, 301-306.

SELEMON, L. D., \& GoldMAN-RAKIC, P. S. (1985). Longitudinal topography and interdigitation of corticostriatal projections in the rhesus monkey. Journal of Neuroscience, 5, 776-794.

Selemon, L. D., \& Goldman-RaKic, P. S. (1988). Common cortical and subcortical targets of the dorsolateral prefrontal and posterior parietal cortices in the rhesus monkey: Evidence for a distributed neural network subserving spatially guided behavior. Journal of Neuroscience, 8, 4049-4068.

SERENO, A. B., \& MAUNSELL, J. H. (1998). Shape selectivity in primate lateral intraparietal cortex. Nature, 395, 500-503.

Shadlen, M. N., \& Newsome, W. T. (2001). Neural basis of a perceptual decision in the parietal cortex (area LIP) of the rhesus monkey. Journal of Neurophysiology, 86, 1916-1936. 
Shallice, T. (1988). From neuropsychology to mental structure. Cambridge: Cambridge University Press.

Sheinberg, D. L., \& Logothetis, N. K. (1997). The role of temporal cortical areas in perceptual organization. Proceedings of the National Academy of Sciences, 94, 3408-3413.

Shibutani, H., SaKata, H., \& Hyvarinen, J. (1984). Saccade and blinking evoked by microstimulation of the posterior parietal association cortex of the monkey. Experimental Brain Research, 55, 1-8.

Shidara, M., \& Richmond, B. J. (2002). Anterior cingulate: Single neuronal signals related to degree of reward expectancy. Science, 296, 1709-1711.

ShIMA, K., Mushiake, H., Saito, N., \& TANJi, J. (1996). Role for cells in the presupplementary motor area in updating motor plans. Proceedings of the National Academy of Sciences, 93, 8694-8698.

SHIMA, K., \& TANJI, J. (1998). Role for cingulate motor area cells in voluntary movement selection based on reward. Science, 282, 1335 1338.

Sigala, N., \& Logothetis, N. K. (2002). Visual categorization shapes feature selectivity in the primate temporal cortex. Nature, $\mathbf{4 1 5}, 318$ 320.

Snyder, L. H., Batista, A. P., \& Andersen, R. A. (1997). Coding of intention in the posterior parietal cortex. Nature, 386, 167-170.

Snyder, L. H., Grieve, K. L., Brotchie, P., \& ANderseN, R. A. (1998). Separate body- and world-referenced representations of visual space in parietal cortex. Nature, 394, 887-891.

Steinmetz, M. A., Connor, C. E., Constantinidis, C., \& McLaughLIN, J. R. (1994). Covert attention suppresses neuronal responses in area $7 \mathrm{a}$ of the posterior parietal cortex. Journal of Neurophysiology, 72, 1020-1023

StEINMETZ, M. A., \& Constantinidis, C. (1995). Neurophysiological evidence for a role of posterior parietal cortex in redirecting visual attention. Cerebral Cortex, 5, 448-456.

Steinmetz, M. A., Motter, B. C., Duffy, C. J., \& Mountcastle, V. B. (1987). Functional properties of parietal visual neurons: Radial organization of directionalities within the visual field. Journal of Neuroscience, 7, 177-191.

STOET, G., \& SNYDER, L. H. (2004). Single neurons in posterior parietal cortex of monkeys encode cognitive set. Neuron, 42, 1003-1012.

Stuphorn, V., TAYlor, T. L., \& Schall, J. D. (2000). Performance monitoring by the supplementary eye field. Nature, 408, 857-860.

Super, H., SpeKreijse, H., \& Lamme, V. A. (2001). A neural correlate of working memory in the monkey primary visual cortex. Science, 293, 120-124.

SUZUKI, W. A., Miller, E. K., \& Desimone, R. (1997). Object and place memory in the macaque entorhinal cortex. Journal of Neurophysiology, 78, 1062-1081.

Takada, M., Nambu, A., Hatanaka, N., Tachibana, Y., Miyachi, S., TAIRA, M., \& INASE, M. (2004). Organization of prefrontal outflow toward frontal motor-related areas in macaque monkeys. European Journal of Neuroscience, 19, 3328-3342.

TANAKA, K., SAITO, H., FuKADA, Y., \& Moriya, M. (1991). Coding visual images of objects in the inferotemporal cortex of the macaque monkey. Journal of Neurophysiology, 66, 170-189.

TANIBUCHI, I., \& GoldMAN-RAKIC, P. S. (2003). Dissociation of spatial-, object-, and sound-coding neurons in the mediodorsal nucleus of the primate thalamus. Journal of Neurophysiology, 89, 1067-1077.

TANJI, J., \& SHIMA, K. (1994). Role for supplementary motor area cells in planning several movements ahead. Nature, 371, 413-416.

Thiele, A., Henning, P., Kubischik, M., \& HoffMAnN, K. P. (2002). Neural mechanisms of saccadic suppression. Science, 295, 24602462.

Tотн, L. J., \& AssaD, J. A. (2002). Dynamic coding of behaviourally relevant stimuli in parietal cortex. Nature, 415, 165-168.

Tovee, M. J., Rolls, E. T., \& Azzopard, P. (1994). Translation invariance in the responses to faces of single neurons in the temporal visual cortical areas of the alert macaque. Journal of Neurophysiology, 72, 1049-1060.

TrEmblaY, L., \& Schultz, W. (1999). Relative reward preference in primate orbitofrontal cortex. Nature, 398, 704-708.

Treue, S., \& Maunsell, J. H. (1996). Attentional modulation of visual motion processing in cortical areas MT and MST. Nature, 382, 539541.

Ungerleider, L. G., Courtney, S. M., \& Haxby, J. V. (1998). A neural system for human visual working memory. Proceedings of the National Academy of Sciences, 95, 883-890.

UNGERLEIDER, L. G., \& MishKIN, M. (1982). Two cortical visual systems. In D. J. Ingle, M. A. Goodale, \& R. J. W. Mansfield (Eds.), Analysis of visual behavior (549-586). Cambridge, MA: MIT Press.

VaAdia, E., Benson, D. A., Hienz, R. D., \& Goldstein, M. H., JR. (1986). Unit study of monkey frontal cortex: Active localization of auditory and of visual stimuli. Journal of Neurophysiology, 56, 934952.

WALKER, A. E. (1940). A cytoarchitectural study of the prefrontal area of the macaque monkey. Journal of Comparative Neurology, 73, 5986.

Wallis, J. D., Anderson, K. C., \& Miller, E. K. (2001). Single neurons in prefrontal cortex encode abstract rules. Nature, 411, 953-956.

Wallis, J. D., Dias, R., Robbins, T. W., \& RoberTs, A. C. (2001). Dissociable contributions of the orbitofrontal and lateral prefrontal cortex of the marmoset to performance on a detour reaching task. European Journal of Neuroscience, 13, 1797-1808.

WAllis, J. D., \& Miller, E. K. (2003a). From rule to response: Neuronal processes in the premotor and prefrontal cortex. Journal of Neurophysiology, 90, 1790-1806.

WALLIS, J. D., \& MILLER, E. K. (2003b). Neuronal activity in primate dorsolateral and orbital prefrontal cortex during performance of a reward preference task. European Journal of Neuroscience, 18, 20692081.

WANG, X. J. (2001). Synaptic reverberation underlying mnemonic persistent activity. Trends in Neurosciences, 24, 455-463.

Wang, X. J., Tegner, J., Constantinidis, C., \& Goldman-Rakic, P. S. (2004). Division of labor among distinct inhibitory neurons in a cortical microcircuit of working memory. Proceedings of the $\mathrm{Na}$ tional Academy of Sciences, 101, 1368-1373.

Wang, Y., MatsuzaKa, Y., Shima, K., \& TANJI, J. (2004). Cingulate cortical cells projecting to monkey frontal eye field and primary motor cortex. NeuroReport, 15, 1559-1563.

Wang, Y., Shima, K., Isoda, M., Sawamura, H., \& TanjI, J. (2002). Spatial distribution and density of prefrontal cortical cells projecting to three sectors of the premotor cortex. NeuroReport, 13, 1341-1344.

Wang, Y., Shima, K., Sawamura, H., \& TanjI, J. (2001). Spatial distribution of cingulate cells projecting to the primary, supplementary, and pre-supplementary motor areas: A retrograde multiple labeling study in the macaque monkey. Neuroscience Research, 39, 39-49.

Watanabe, Y., \& Funahashi, S. (2004a). Neuronal activity throughout the primate mediodorsal nucleus of the thalamus during oculomotor delayed-responses: I. Cue-, delay-, and response-period activity. Journal of Neurophysiology, 92, 1738-1755.

Watanabe, Y., \& Funahashi, S. (2004b). Neuronal activity throughout the primate mediodorsal nucleus of the thalamus during oculomotor delayed-responses: II. Activity encoding visual versus motor signal. Journal of Neurophysiology, 92, 1756-1769.

Watanabe-SaWaguchi, K., KubOTa, K., \& ARIKUnI, T. (1991). Cytoarchitecture and intrafrontal connections of the frontal cortex of the brain of the hamadryas baboon (Papio hamadryas). Journal of Comparative Neurology, 311, 108-133.

Webster, M. J., BACHEVALIER, J., \& UNGerleider, L. G. (1994). Connections of inferior temporal areas TEO and TE with parietal and frontal cortex in macaque monkeys. Cerebral Cortex, 4, 470-483.

White, I. M., \& Wise, S. P. (1999). Rule-dependent neuronal activity in the prefrontal cortex. Experimental Brain Research, 126, 315-335.

Williams, G. V., \& Goldman-RaKic, P. S. (1995). Modulation of memory fields by dopamine D1 receptors in prefrontal cortex. $\mathrm{Na}$ ture, 376, 572-575.

WILLIAMS, S. M., \& GoldMAN-RAKIC, P. S. (1993). Characterization of the dopaminergic innervation of the primate frontal cortex using a dopamine-specific antibody. Cerebral Cortex, 3, 199-222.

Wilson, F. A., Ó Scalaidhe, S. P., \& Goldman-RaKic, P. S. (1993). Dissociation of object and spatial processing domains in primate prefrontal cortex. Science, 260, 1955-1958. 
Wise, S. P., Murray, E. A., \& Gerfen, C. R. (1996). The frontal cortexbasal ganglia system in primates. Critical Reviews in Neurobiology, 10, 317-356.

YAKOVLeV, V., Fusi, S., Berman, E., \& Zohary, E. (1998). Inter-trial neuronal activity in inferior temporal cortex: A putative vehicle to generate long-term visual associations. Nature Neuroscience, 1, 310-317.

YANG, C. R., \& SEamans, J. K. (1996). Dopamine D1 receptor actions in layers V-VI rat prefrontal cortex neurons in vitro: Modulation of dendritic-somatic signal integration. Journal of Neuroscience, 16, 1922-1935.
ZeKI, S. M. (1978). Uniformity and diversity of structure and function in rhesus monkey prestriate visual cortex. Journal of Physiology, 277, 273-290.

ZHOU, Y. D., \& Fuster, J. M. (1996). Mnemonic neuronal activity in somatosensory cortex. Proceedings of the National Academy of Sciences, 93, 10533-10537.

(Manuscript received July 26, 2004;

revision accepted for publication October 19, 2004.) 